\title{
Fauna e industria sobre materia dura de origen animal del lugar sagrado de la Cultura de las Motillas: Castillejo del Bonete (Terrinches, Ciudad Real)
}

\author{
Fauna and animal hard raw material of the \\ sacred place of the Motilla Culture: Castillejo \\ del Bonete (Terrinches, Ciudad Real)
}

LUIS BENÍTEZ DE LUGO ENRICH
Dpto. de Prehistoria y Arqueología
Centro Asociado de Ciudad Real UNED
Calle Seis de Junio, 55
1330o Valdepeñas (Ciudad Real)
Ibenitez@valdepenas.uned.es
http://orcid.org/oooo-0003-2000-6293

CÉSAR LAPLANA CONESA

Museo Arqueológico Regional

Plaza de las Bernardas, $s / n$

28801 Alcalá de Henares (Madrid)

cesar.laplana.conesa@madrid.org

https://orcid.org/00oo-0002-2067-4091

AMALIA PÉREZ ROMERO

Laboratorio Evolución Humana

Dpto. CC. Históricas y Geografía

Edificio I+D+i, Universidad de Burgos

Plaza Misael Bañuelos s/n

09001 Burgos

apromero14@gmail.com

https://orcid.org/0000-0002-9283-7574
Ma ÁNGeles GALINDO-PELLICENA Centro Mixto UCM-ISCIII de Evolución y Comportamiento Humanos

Calle Monforte de Lemos, 5 - pabellón 14 28029 Madrid

mariangape79@hotmail.com

https://orcid.org/0000-0003-3331-1043

GABRIEL MENCHÉN HERREROS

Anthropos, S.L. Aptdo. de Correos 238

13300 Valdepeñas (Ciudad Real)

anthropos@estudio-arqueologia.es

https://orcid.org/0000-0001-9425-5415

JosÉ LUIS FUENTES SÁNCHEZ

Universidad de Granada/Oppida

Calle Gloria Fuertes, 7

13170 Miguelturra (Ciudad Real)

jose.l.fuentes.s@hotmail.com

https://orcid.org/0000-0002-9312-9035
ÁNGEL C. DOMínguez GARCíA Dpto. de Geodinámica, Estratigrafía y Paleontología

Facultad de Ciencias Geológicas Universidad Complutense de Madrid Calle José Antonio Novais, 12 - 28040 Madrid angelcdo@ucm.es https://orcid.org/0000-0003-1762-6328

NORBERTO PALOMARES ZUMAJO Anthropos, S.L. Aptdo. de Correos 238 13300 Valdepeñas (Ciudad Real) anthropos@estudio-arqueologia.es https://orcid.org/o0oo-0002-8728-7221

DOMINGO C. SALAZAR-GARCÍA

Departament de Prehistòria,

Arqueologia i Història Antiga

Universitat de València

domingocarlos.salazar@uv.es

https://orcid.org/0000-0002-8017-0194

\section{Resumen}

En los últimos años revistas científicas han publicado diversos estudios (cerámica, metal, material lítico, etc.) sobre Castillejo del Bonete. Este trabajo presenta datos inéditos sobre la industria ósea, micro y macromamíferos encontrados en este yacimiento. La industria elaborada sobre materia dura de origen animal está constituida principalmente por piezas elaboradas con hueso, asta o dientes, que fueron utilizados como medios de producción o complementos para vestir y adornar a los difuntos, o tallar ídolos. El estudio de los micromamíferos aporta información sobre el final del uso de estos túmulos, así como sobre aspectos ambientales. Los perfiles de mortalidad de los grandes mamíferos sugieren una explotación mixta, tanto de productos primarios (carne) y secundarios (leche, lana y posibles animales de carga o tracción) en el caso de los ovicaprinos, bovinos y cerdos. Las piezas arqueológicas depositadas aquí fueron puestas al servicio de un ritual creado en torno a los ancestros y a un culto solar desde el Calcolítico hasta la Edad del Bronce. Se aportan dos nuevas dataciones radiocarbónicas del yacimiento. La primera está obtenida de una vértebra de ovicaprino, que marca el momento de monumentalización de la cueva utilizada como cámara funeraria, mediante la construcción del Gran Túmulo 1. La segunda permite datar el momento de uso del Túmulo 2.

Palabras clave: Arqueología prehistórica, Arqueología Funeraria, Calcolítico, Edad del Bronce, Paleobioarqueología, Arqueozoología 


\section{Abstract}

In recent years, scientific journals have published several studies (ceramics, metal, lithic material, etc.) on Castillejo del Bonete. This work presents unpublished data on the bone industry, small and large mammals found in this site. Bone artifacts are mainly made up of from bone, antler or teeth, which were used as tools for production or accessories to dress and adorn the deceased, or to make idols. The study of small mammals provides information on the end of the use of these burial mounds, as well as on environmental aspects. The mortality profiles of big domestic mammals (ovicaprines, bovines and pigs) suggest a mixed exploitation, such primary (meat) as secondary (milk, wool and probably traction use) products The archaeological pieces deposited here were put at the service of a ritual created around the ancestors and a solar cult from the Chalcolithic until the Bronze Age. Two new radiocarbon dates of the site are provided, one of them obtained from an ovicaprine vertebra, which marks the moment of monumentalization of the cave used as a burial chamber, through the construction of the Great Mound 1. The second one allows to date the time of use of the Tumulus 2.

Key words: Prehistoric Archaeology, Funerary Archaeology, Cooper Age, Bronze Age, Paleobioarchaeology, Archaeozoology

\section{Introducción}

Las investigaciones arqueológicas en Castillejo del Bonete comenzaron en 2003. Mediante una corta campaña de tan solo dos semanas fueron abiertos $36 \mathrm{~m}^{2}$ del yacimiento, que permitieron descubrir potentes muros curvos de un túmulo y una cultura material enmarcable en el Bronce de La Mancha (figura I). $\mathrm{Al}$ año siguiente se desarrolló una campaña similar, descubriéndose la potencia de ese túmulo (2,Io $\mathrm{m}$ de tierra y piedras) y, bajo él, una cueva desconocida, que había permanecido oculta y sellada desde la Prehistoria. Entramos dos veces a la cueva y la clausuramos, quedando así hasta que años después pudo empezar a ser estudiada. En 2005 fuimos invitados por la Administración regional al Museo de Cuenca para exponer una primera valoración sobre el yacimiento en el marco de una reunión científica. En aquel momento, con poco más de $50 \mathrm{~m}^{2}$ abiertos y la cueva sin estudiar, utilizamos el paradigma establecido sobre el Bronce de La Mancha para explicar el yacimiento: con todas las cautelas y señalando que las valoraciones eran muy preliminares, indicamos que el sitio podría ser una cueva fortificada utilizada como captación de agua, en una zona del Bronce de La Mancha en la que no hay motillas (Benítez de Lugo et alii, 2007). Lo que resulta evidente desde un primer momento para cualquiera que conociera el lugar o el yacimiento es que el emplazamiento no se puede clasificar ni como morra ni como motilla, puesto que se ubica en ladera, sobre el borde meridional de la Meseta, en un lugar elevado muy visible, pero también con cotas superiores muy próximas hacia el noreste que dominan el enclave por ser más altas; sería, en consecuencia, fácilmente atacable desde esa zona; realmente la construcción de Castillejo del Bonete no se realizó en clave defensiva; no cuenta con torres, bastiones, murallas ni puertas fortificadas. No se construyó sobre un acuífero ni encima de un montículo para facilitar su defensa. Hoy sabemos que su emplazamiento deriva de la cueva a la que monumentaliza, situada sobre un corredor natural, utilizado tradicionalmente como vía ganadera y de paso interregional (figura 2). Se trata, por el momento, del único lugar estudiado en el área cultural del Bronce de La Mancha sin hábitat documentado. Es preciso recordar, además, que su cultura material no se limita a la Edad del Bronce y señala con claridad unos orígenes calcolíticos. El monumento se edificó en la ladera meridional de la Meseta castellana sobre un punto con gran visibilidad y que se ve durante muchos kilómetros desde una vía natural de paso que discurre al sureste de la provincia de Ciudad Real, entre las cuencas hidrográficas del Guadiana y del Guadalquivir; su situación es privilegiada; ese corredor ha permitido durante siglos conectar Levante, la Meseta y Alta Andalucía, funcionando como vía trashumante y de circulación para personas, animales, ideas y cargas, conforme al modelo de comunidades políticas paritarias (peer polity interaction) (Blanco y Esparza, 20I9). 


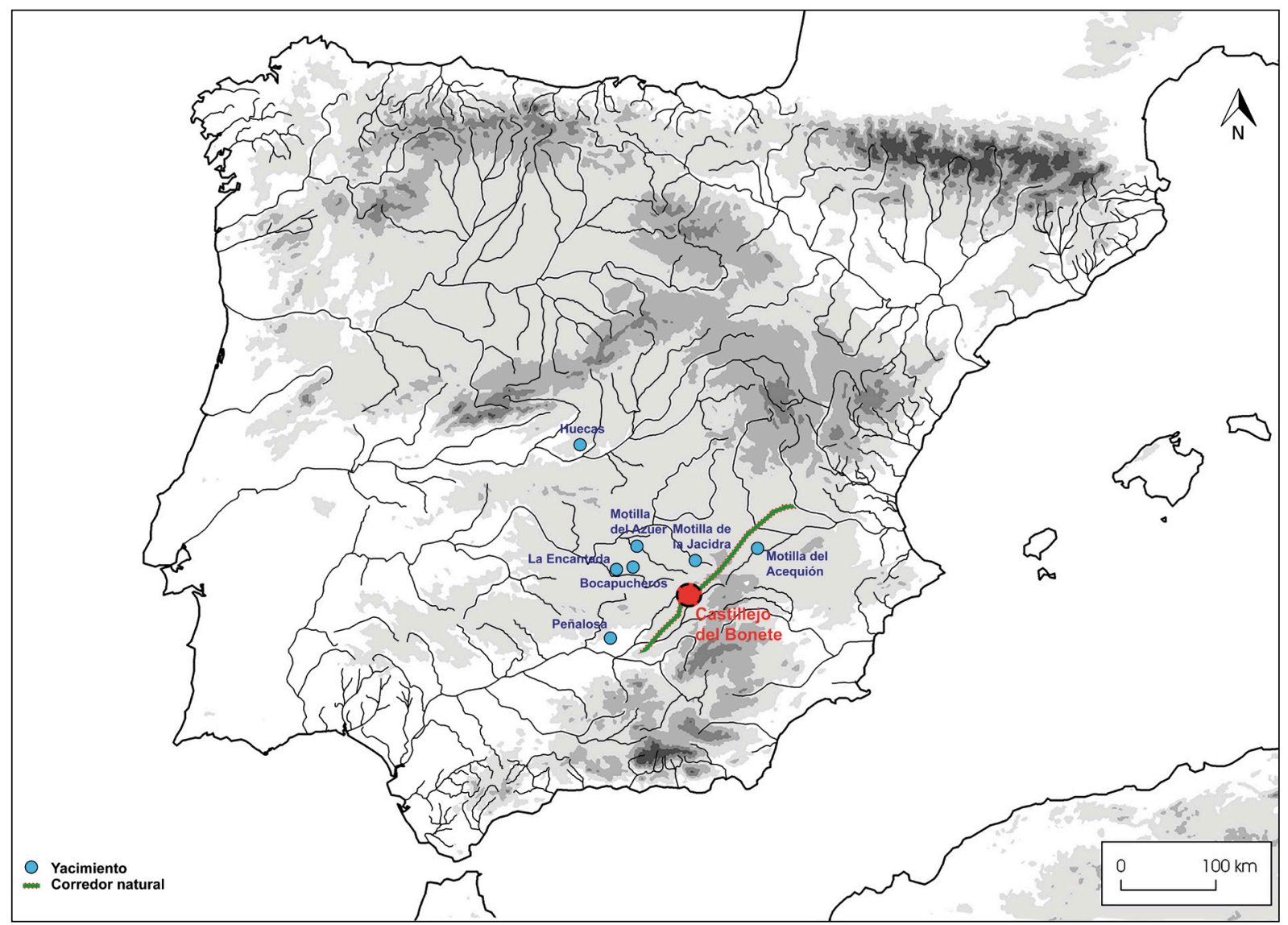

Figura 1. Mapa general de localización. Castillejo del Bonete, en relación con otros conocidos yacimientos sincrónicos próximos y el corredor natural de paso que comunica Andalucía, la Meseta y Levante

Figure 1. General location map. Castillejo del Bonete, in relation to other well-known nearby synchronous sites and the natural passage corridor that connects Andalusia, the Meseta and Levante

Una década después del inicio de los trabajos en el yacimiento concluimos un estudio hidrogeoarqueológico dirigido a comprobar si la cueva podía haber sido un punto fortificado utilizado para el aprovisionamiento de agua o como lugar de hábitat: no lo era. No tuvimos inconveniente en publicar en la primera revista de Prehistoria española — que nos concedió su portada en ese número- que nuestra hipótesis inicial no había sido acertada (Benítez de Lugo et alii, 20I4a y 20I4b). Castillejo del Bonete empezaba a poner de manifiesto que el viejo paradigma del Bronce de La Mancha necesitaba un reajuste para, a pesar de las inercias y resistencias, encajar y explicar esta nueva clase de yacimiento, así como superar una obsoleta división en series cronológicas histórico-culturales y fases insuficientemente definidas para el Bronce de La Mancha, para dar más peso a las dataciones radiocarbónicas. Y también la necesidad de analizar en detalle las evidencias de continuidad cultural entre el Calcolítico y la Edad del Bronce en el sur de la Meseta (algo planteado por Balsera et alii, 2015), o el origen y el final de la Cultura de las Motillas, que permanecía sin explicaciones satisfactorias tras más de cincuenta años de investigaciones arqueológicas; una cultura que, como venimos señalando desde 2010 , se encuentra intimamente ligada a la crisis social y ambiental derivada del estrés por déficit hídrico producida por el Evento Climático 4.2 cal BP, bien representada en el histograma polínico de Castillejo del Bonete. Esta reconstrucción ambiental es coincidente con la de la motilla de El Azuer y revela momentos alternos de mayor aridez y temperatura fría con otros que no lo fueron tanto (Benítez de Lugo y Mejías, 2015, 2016a, 20I6b, 20I7, 202ob; Benítez de Lugo, 2010, 20II, 20I8a y 20I8b; Benítez de Lugo et alii, 2015b, 2020c). En esas publicaciones, y ya con $676 \mathrm{~m}^{2}$ de yacimiento abierto - aunque con la cueva aún sin estudiar-, 


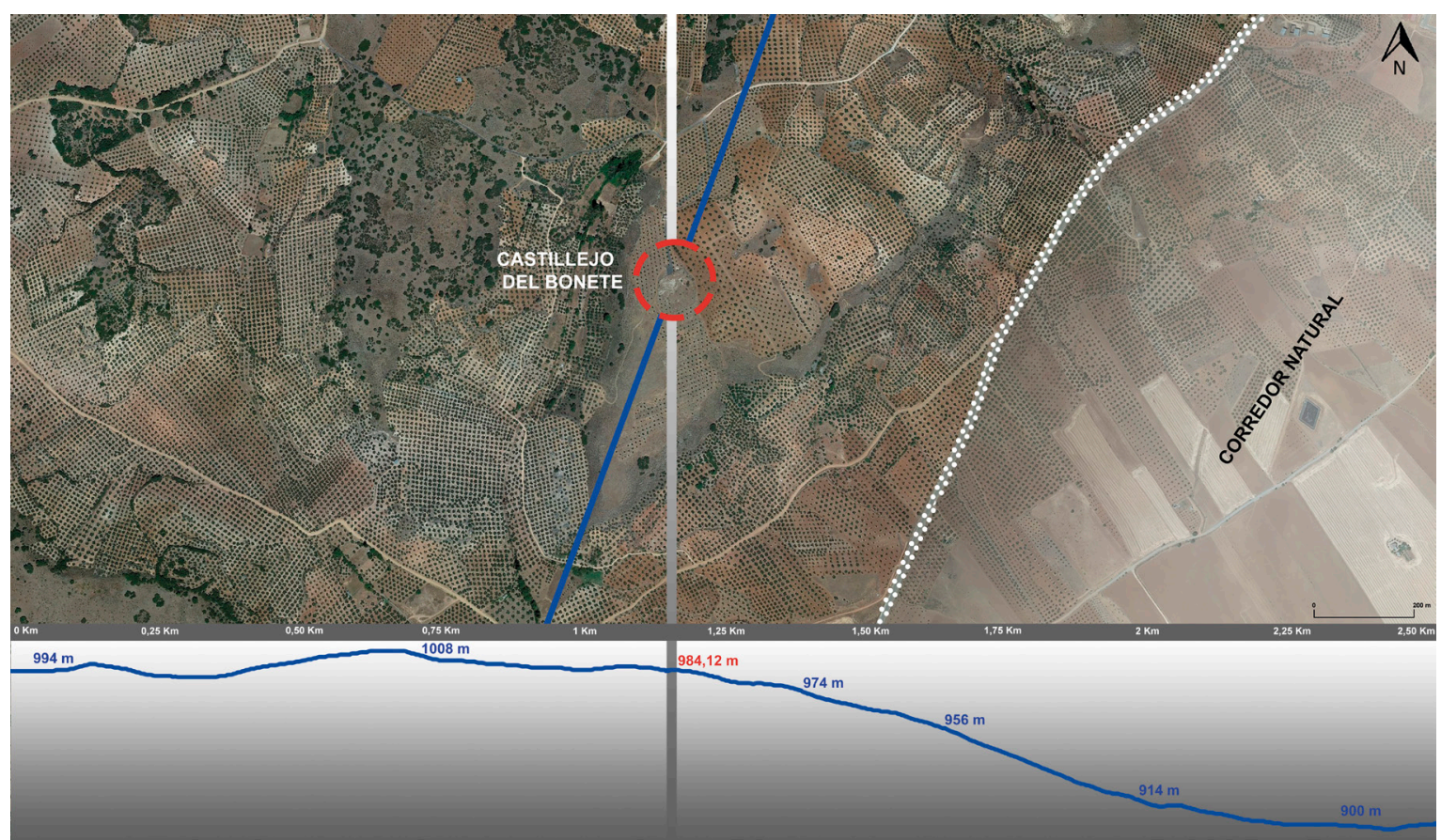

Figura 2. Corte topográfico. Lugar donde se encuentra Castillejo del Bonete, sobre un corredor natural de paso, en ladera y en un lugar con gran visibilidad pero fácilmente dominable desde cotas superiores

Figure 2. Topographic section. Place where Castillejo del Bonete is located, on a natural passage corridor, on the slope and in a place with great visibility but easily dominated from higher heights

resultaba evidente que los muros y acumulaciones de tierra y piedras no correspondían a estructuras de hábitat ni a derrumbes de una fortificación, sino a los corredores, depósitos rituales y estructuras asociadas a un gran túmulo que no era macizo. En su interior se han documentado recintos y depósitos, funerarios y de materiales.

Seguidamente, investigaciones arqueoastronómicas permitieron constatar que Castillejo del Bonete fue concebido como un monumento solar impresionante (Benítez de Lugo y Esteban, 2018), relacionable con Stonehenge o Newgrange (Serrano et alii, 20I7: 137-138). De esta forma se dio un paso importante en la reconstrucción de aspectos sociales y simbólicos de esta sociedad, en gran parte desconocidos hasta hoy. Progresivamente, mediante diferentes estudios específicos, se han ido publicando los materiales arqueológicos aquí enterrados (Benítez de Lugo et alii, 2014-2015, 2015a, 2015b, 2020a; Delvene et alii, 2018; Fernández Martín et alii, 2018; Montero et alii, 2014; Odriozola et alii, 2016; Polo et alii, 2015; Salazar-García et alii, 2013). La presencia de objetos de la vida cotidiana en este lugar pone de manifiesto que esta clase de piezas no siempre fueron empleadas en poblados o los lugares de uso cotidiano, sino que con frecuencia tuvieron una segunda vida al servicio de los difuntos. Castillejo del Bonete fue un lugar de utilización muy prolongada, pero no permanente, sino de uso reiterado. Aquí se realizaron depósitos con ofrendas y se enterraron personas con sus objetos cotidianos durante siglos, siendo alterados los depósitos más antiguos al introducirse los más recientes.

Últimamente se ha sabido que Castillejo del Bonete refleja el paradigma de la rápida desaparición de los varones peninsulares en la Prehistoria Reciente, relacionada con la llegada de descendientes de pobladores de las estepas orientales de Europa con cromosoma Y Rib (seguramente en relación directa con el Evento Climático 4.2 cal BP). Uno de esos varones de ascendencia oriental está enterrado en la Tumba 4 junto a una mujer genéticamente compatible con las poblaciones de la península ibérica de la Edad del Cobre, sin ascendencia de las estepas, con evidencia isotópica de probable consumo de recursos marinos y portadora de objetos personales de marfil (Olalde et alii, 20rg; Salazar-García et alii, 20I3: I2). Aunque hay decenas de yacimientos 

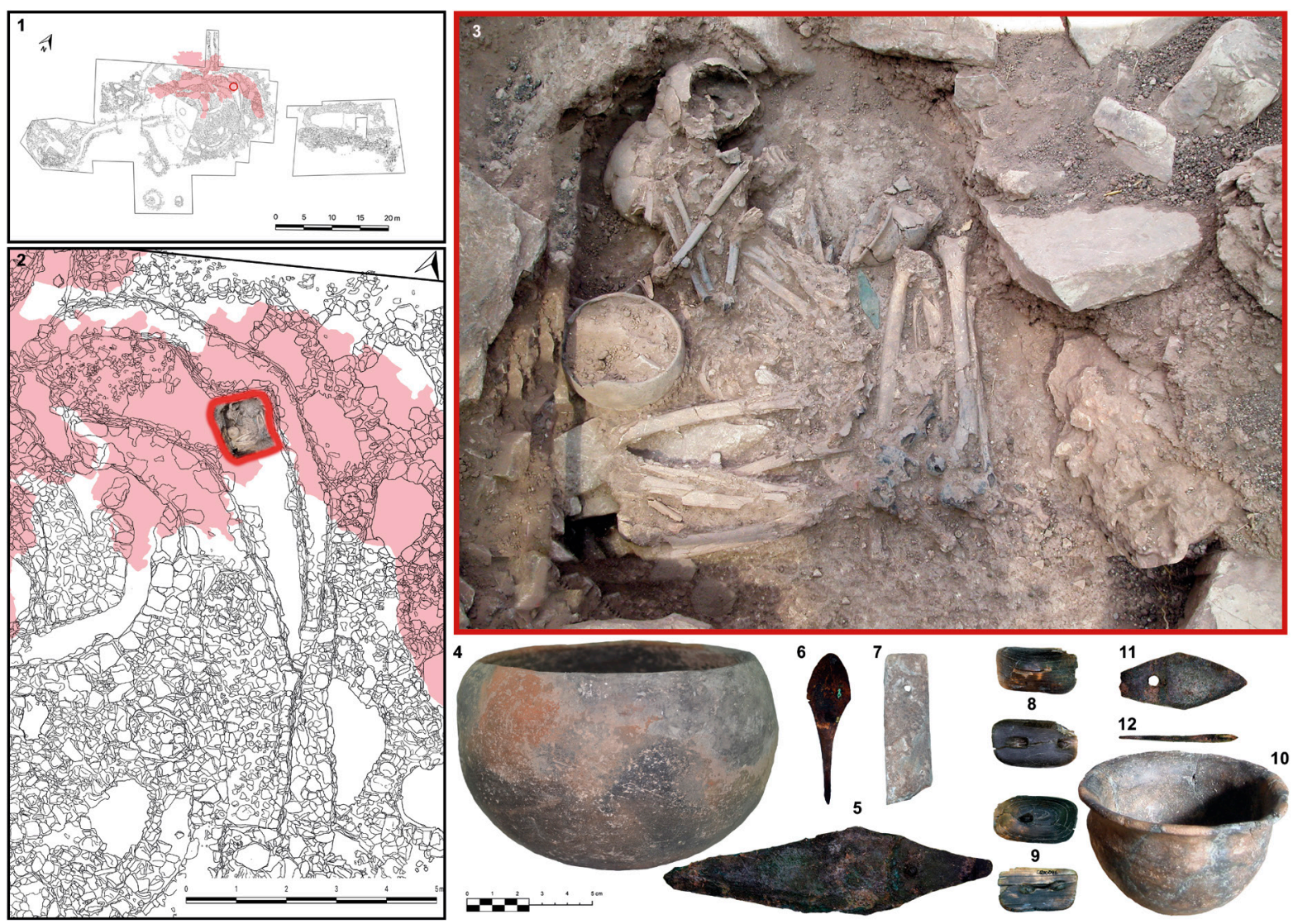

Figura 3. Tumba 4: 1. Localización en el Gran Túmulo 1, sobre la cueva sepulcral funeraria (en rosa pálido). 2. Ubicación dentro del Recinto 1, adosado al Gran Túmulo 1. 3. Restos humanos de dos individuos con su ajuar. 4. Ajuar: cuchillo de dos remaches de cobre arsenicado (5), punta de flecha tipo «Palmela» (6), brazal de arquero (7), botones de marfil (8 y 9), cuchillo muy gastado (11), punzón (12) y dos recipientes cerámicos

Figure 3. 1. Tomb 4: 1. Location in Great Tumulus 1, above the funerary sepulchral cave (in pale pink). 2. Location within Enclosure 1, attached to Great Tumulus 1. 3. Human remains of two individuals with their trousseau. 4. Trousseau: knife with two arsenic copper rivets (5), "Palmela" type arrowhead (6), archer's armband (7), ivory buttons (8 and 9), worn knife (11), awl (12) and two ceramic vessels (4 and 10)

analizados con motivo de este estudio genético peninsular al que nos referimos, Castillejo del Bonete es el único en el que se ha encontrado una inhumación doble de dos individuos — uno masculino y otro femenino- con ancestrías genéticas diferentes, ejemplo de la simbiosis cultural que se produjo. Esta tumba - la Tumba 4 - incluía objetos de la vida cotidiana como ajuar: un cuenco carenado, un cuenco globular que contenía un punzón y un pequeño cuchillo muy gastado, ambos de cobre arsenicado, dos botones de marfil sobre el cuerpo de la mujer y, sobre el varón, un cuchillo de cobre con un remache en su cintura y un brazal de arquero en su antebrazo (Benítez de Lugo et alii, 2014a: 167-I67 y 20I4b: 8r; (figura 3). Las tres primeras tumbas documentadas (tumbas I, 2 y 3 , enterradas en el cuerpo del túmulo principal a un nivel muy superficial), carecían de ajuar. Ni la Tumba 5 (que amortiza el Corredor 3 , también fuera de la cueva), ni los enterramientos localizados dentro de la cueva (en estudio), cuentan con elementos de ajuar característicos en la Cultura de El Argar, como son las diademas, alabardas o espadas. La cultura material de este lugar remite sin duda al Bronce de La Mancha y a sus antecedentes.

En definitiva, en 2020, con I $015,4 \mathrm{~m}^{2}$ del yacimiento excavados ( $89 \mathrm{~m}^{2}$ de cueva y $926,4 \mathrm{~m}^{2}$ al exterior), Castillejo del Bonete se revela como una reserva arqueológica de gran interés para entender mejor la Cultura de las Motillas, los rituales de la Prehistoria Reciente al sur de la Meseta y la continuidad cultural entre el III y II milenios cal BC. Tal y como hemos explicado en publicaciones previas, es un lugar en donde reiteradamente se practicaron 


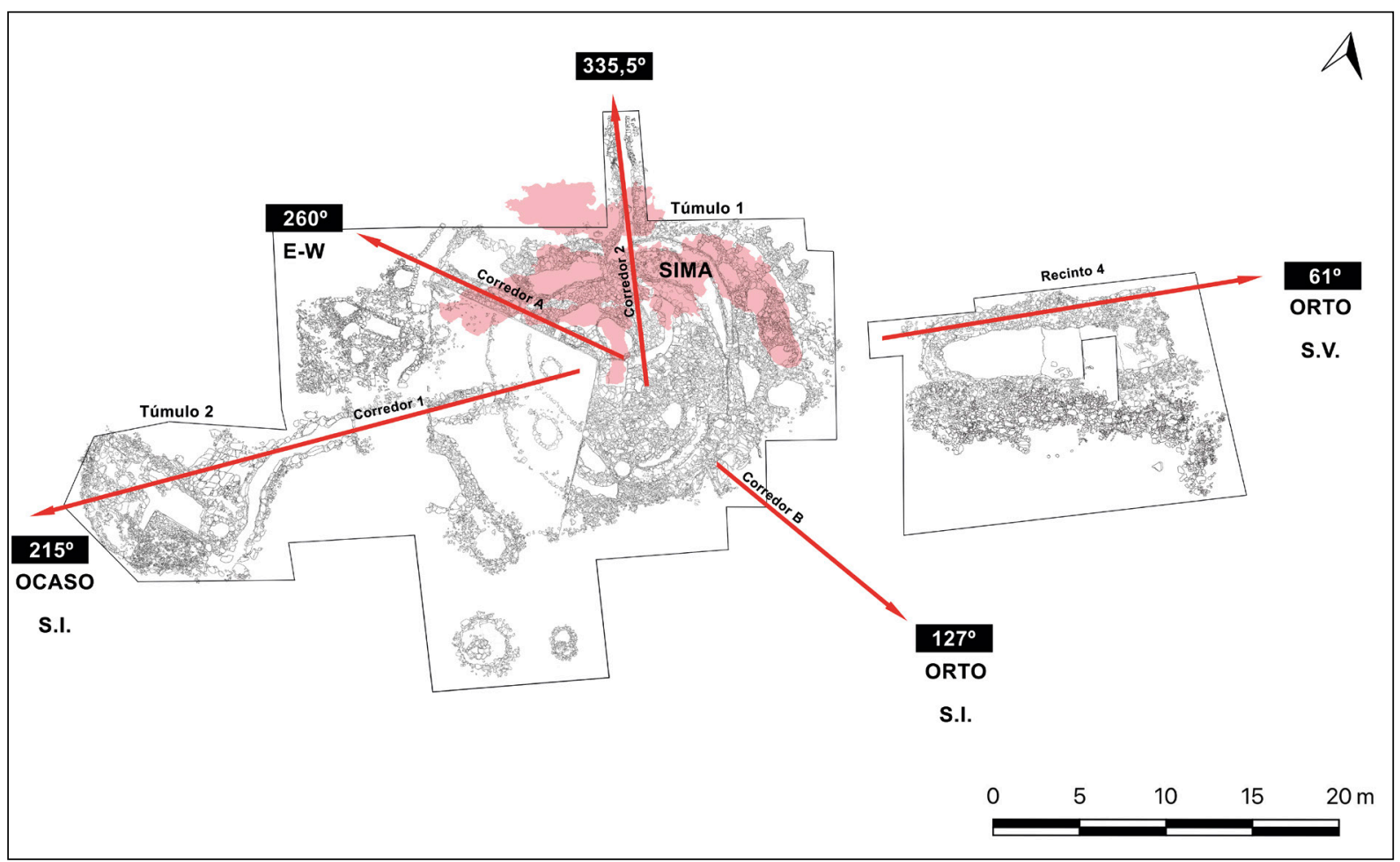

Figura 4. Planta general del yacimiento (en blanco y negro) y de la cueva subterránea (en rosa pálido). Orientaciones astronómicas. Las flechas revelan que el monumento fue construido con atención a eventos solares que funcionaron como marcadores calendáricos

Figure 4. General plan of the site (in black and white) and of the underground cave (in pale pink). Astronomical orientations to the winter (SI) and summer (SV) solstices. The arrows reveal that the monument was built with attention to solar events that functioned as calendrical markers

actividades rituales durante un milenio a lo largo del Calcolítico y la Edad del Bronce, cuyos argumentos continuados fueron la gestión de los ancestros y de la muerte, en un contexto ideológico de utilización política de la importancia conferida a los antepasados, así como el ciclo muerte-resurrección del sol (Esteban y Benítez de Lugo, 2016) (figura 4). Aunque el estudio antropológico está aún pendiente de conclusión, podemos avanzar que los cuerpos aquí depositados corresponden a todas las edades y géneros, y proceden de diferentes lugares geográficos. Es decir, Castillejo del Bonete fue un lugar central; un referente al que acudían a depositar a sus muertos gentes diversas. Así parecen indicarlo la estela funeraria elaborada sobre caliza fosilífera alóctona (con Pectinidae), procedente de la provincia de Albacete, destinada a un enterramiento y encontrada en el interior de la cueva sepulcral (Benítez de Lugo et alii, 2020a: 76); o la mujer de la Tumba 4, alimentada con recursos marinos (Salazar-García et alii, 2013). Algunos de los formatos rituales aquí detectados y desconocidos hasta ahora en el Bronce de La Mancha son probables celebraciones de comensalidad, ofrendas a los difuntos de objetos de la vida cotidiana con características muy diversas, la orientación de las arquitecturas a los marcadores solsticiales (tanto de invierno como de verano) o el recurso a la solución iconográfica megalítica consistente en monumentalizar el paisaje mediante monumentos tumulares que fueron objeto de reiteradas aperturas y cierres para depositar, tanto en su cuerpo como en el interior de la cueva sepulcral usada como cámara funeraria, objetos y personas fallecidas (probablemente no todas las de la comunidad). En Castillejo del Bonete la mayor entre todas las construcciones es el Gran Túmulo I, que tiene 44,2 $\mathrm{m}$ de diámetro en su eje norte/sur ( $80 \mathrm{~m}$ de perímetro); el Túmulo 2 tiene I2,I $\mathrm{m}$ (32,6 $\mathrm{m}$ de perímetro). El lugar cuenta con, al menos, cinco corredores de diferente tipo (unos abocinados para permitir la entrada de los rayos solares al interior del monumento al amanecer y ocaso durante muchas semanas; otros de 


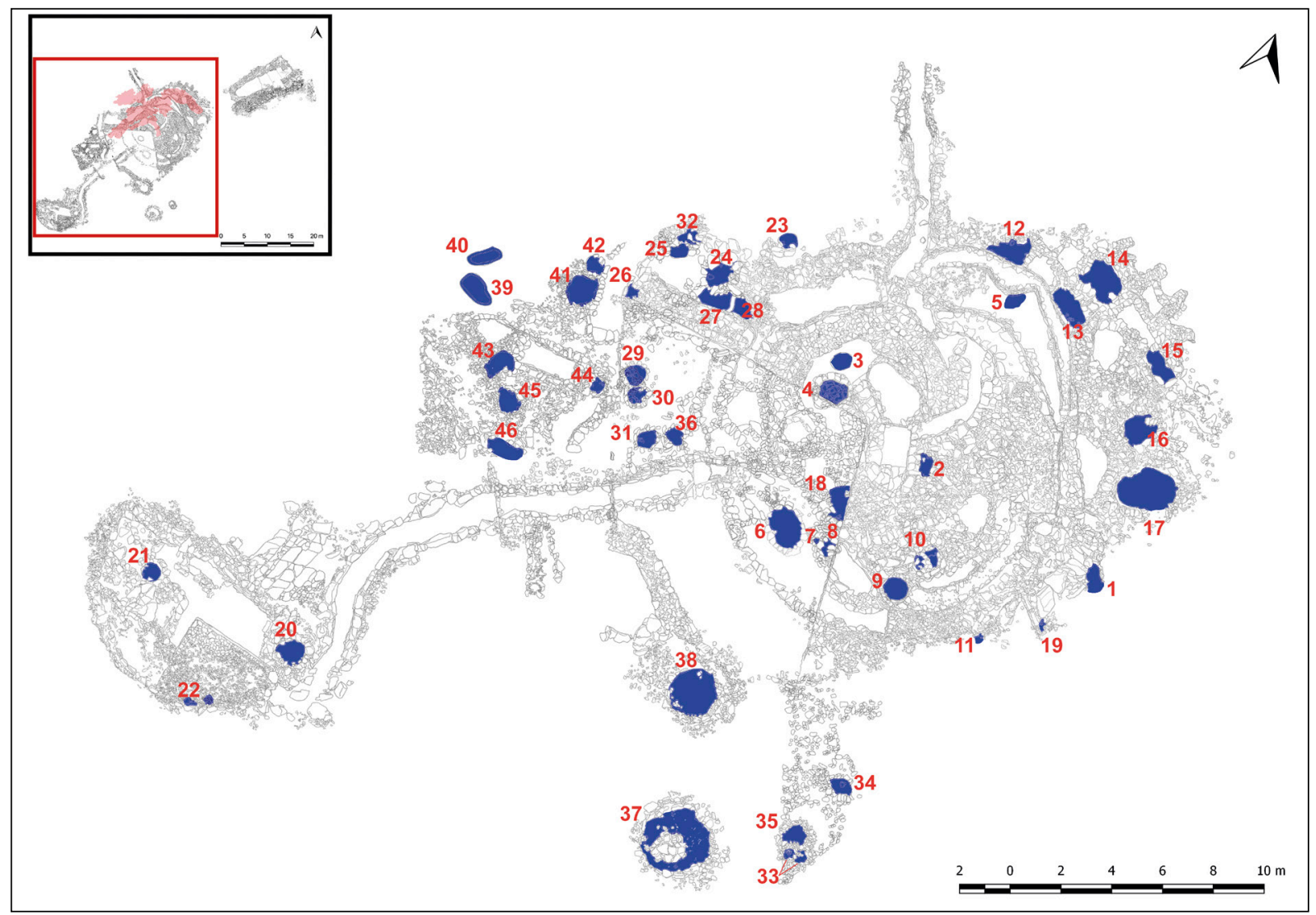

Figura 5. Depósitos. Fosas abiertas y cerradas en el cuerpo de los túmulos 1 y 2

Figure 5. Deposits. Open and closed pits in the body of burial mounds 1 and 2

planta sinuosa, etc.) y fue levantado sobre una cueva sepulcral colectiva en un momento de creciente jerarquización social y atribución asimétrica de derechos sobre los recursos de la comunidad. En el cuerpo de este túmulo y a su alrededor hay decenas de fosas o estructuras siliformes de diferente tamaño y clase, que fueron abiertas en su cuerpo para ser posteriormente cerradas con tierra y piedras, a fin de restablecer la fisionomía tumular del monumento $y$ tras haber depositado en ellas materiales como fragmentos de fauna y cerámicos (probablemente procedentes de banquetes), metales y objetos varios. E1 Recinto 4 es un edificio de notables dimensiones que está próximo al Túmulo y y probablemente se relaciona con actividades ceremoniales, en el que no existen enterramientos. Perfectamente pudo tratarse de un lugar destinado a oraciones y rezos (figura 5). Por todo el yacimiento existen restos óseos humanos y de fauna dispersos, formando parte del sedimento pardo oscuro que caracteriza el sitio y es diferente del entorno.
Una vez publicados estudios sobre metales, cerámicas, marfiles, pólenes, carbones, genética, Hidrogeología, Arqueoastronomía o material lítico de Castillejo del Bonete, este trabajo presenta, por vez primera, el avance del estudio sobre los restos macrofaunísticos, además de los útiles que se han recuperado tanto dentro de la cueva como al exterior, elaborados sobre materia dura de origen animal.La investigación permite avanzar en el conocimiento de este yacimiento singular y averiguar la estrategia de subsistencia de las gentes que lo utilizaron, su modo de vida y algunos aspectos sociales y rituales, a partir de los animales que les acompañaban y los útiles que utilizaban. Asimismo, se presentan las implicaciones extraídas a partir de un primer estudio de los restos de micromamíferos recuperados en el interior de la cueva.

\section{Contexto arqueológico}

La fauna y la industria ósea objeto de estudio (ver tabla I) se han documentado por todo el yacimiento, 


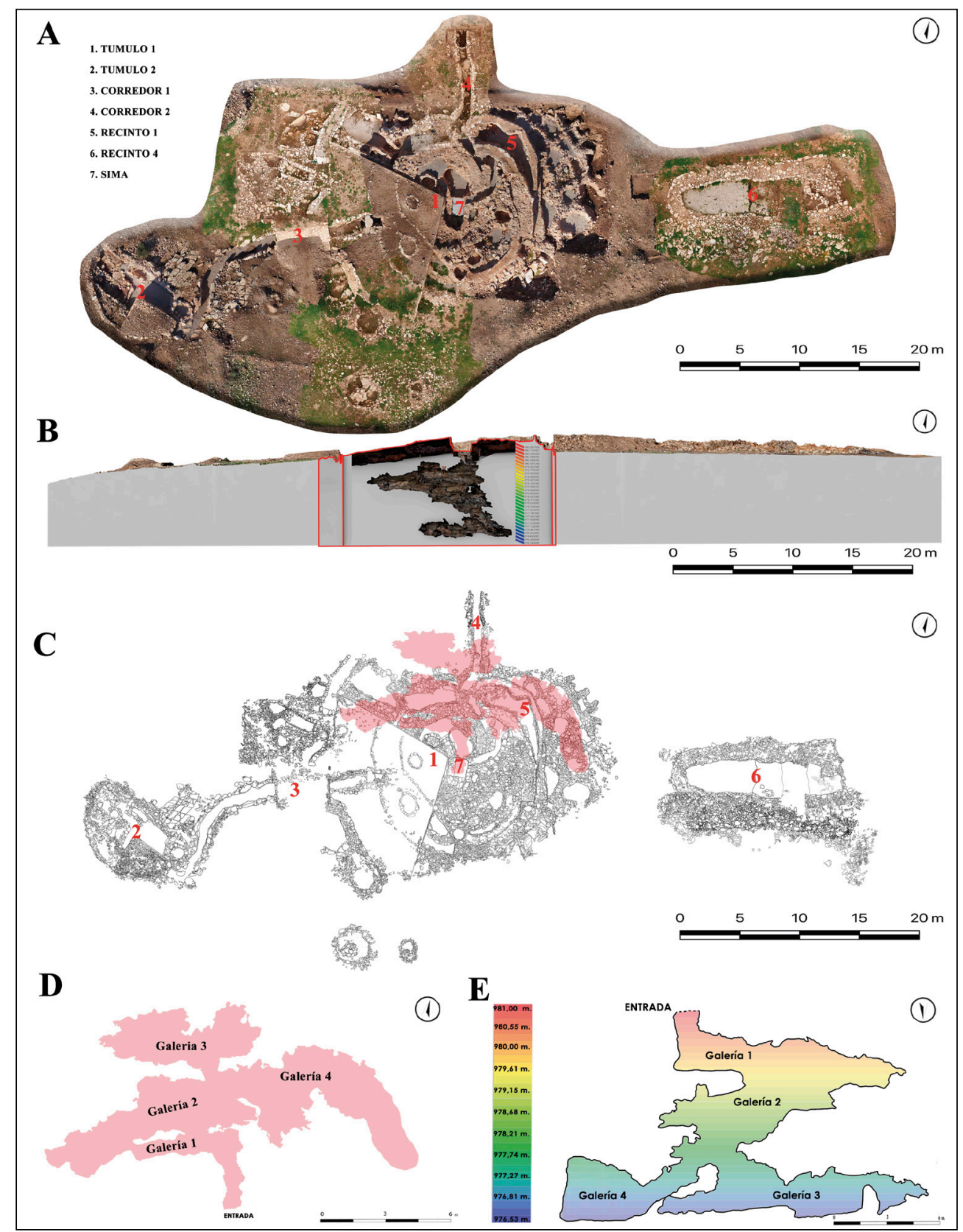

Figura 6. Planta (A, C, D) y sección (B, E) actualizadas de Castillejo del Bonete

Figur6 6. Updated plan (A, C, D) and section (B, E) of Castillejo del Bonete

tanto en contextos cerrados como en posiciones secundarias. Los movimientos de material se han producido por las sucesivas acciones derivadas del uso de este lugar. A continuación, se exponen los datos más relevantes acerca de los hallazgos que proporcionan información de mayor interés; se trata del material procedente de contextos en posición primaria. El material más significativo se ha encontrado tanto en el interior de la cueva sepulcral monumentalizada como al exterior de la misma, dentro del cuerpo principal del Gran Túmulo r o en sus alrededores (figura 6). Ver figura 5 para localización.

\subsection{Gran Túmulo 1}

Fuera de la cueva se recuperaron varias piezas asociadas en muchos casos a fosas o depósitos de carácter oferente (figura 5) (Benítez de Lugo et alii, 20I4a: I62, r64). Se trata de aperturas de diferente tamaño en el cuerpo del túmulo (Túmulo I) que, tras ser abiertas para 


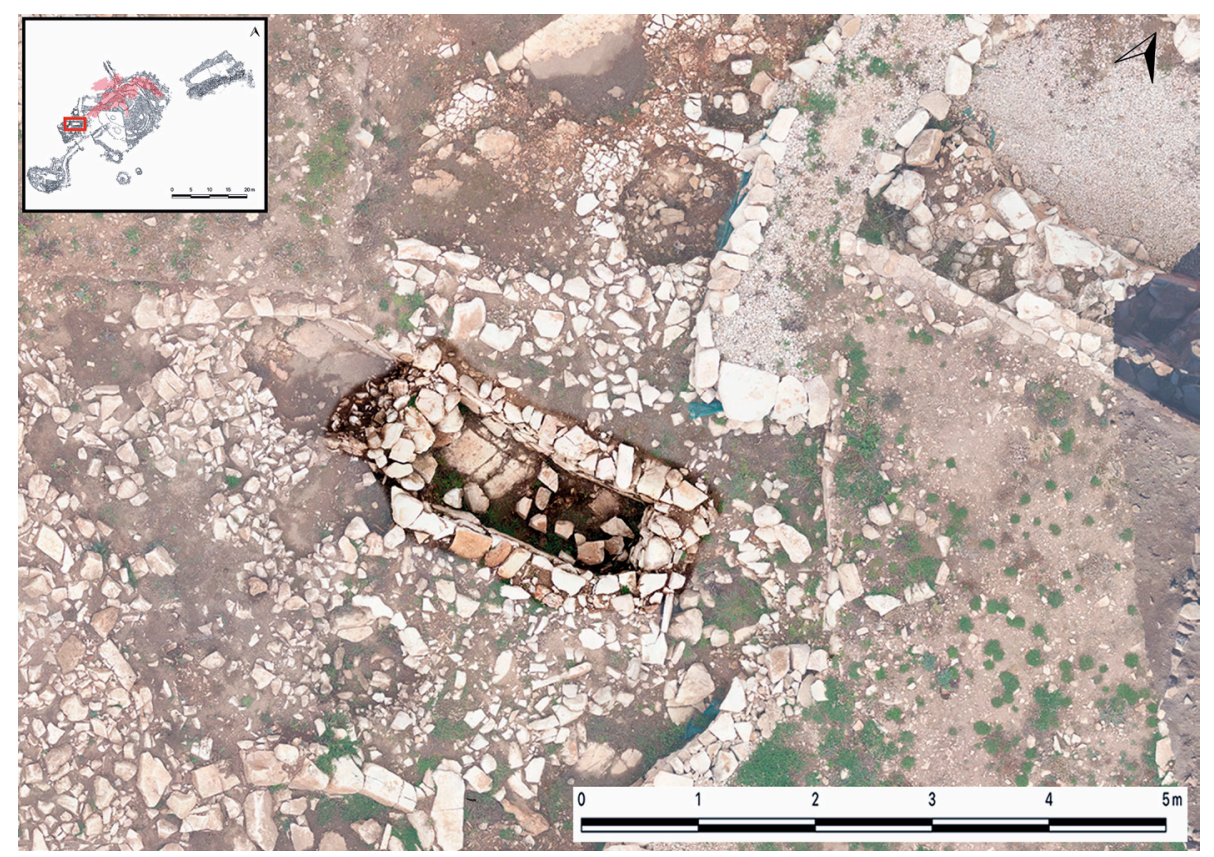

Figura 7. Localización de la Tumba 5, amortizando el Corredor 3

Figure 7. Location of Tomb 5, amortizing Corridor 3

depositar algo en su interior, fueron tapadas con tierra y piedras. Ver tabla i sobre el material objeto de estudio en el Gran Túmulo I.

\subsection{Túmulo 2}

Otra de las zonas importantes del yacimiento es el Túmulo 2, localizado al oeste del Gran Túmulo I. Se trata de una estructura tumular secundaria, asociada al túmulo principal por medio de un corredor sinuoso (el Corredor I). Ver tabla I con el material objeto de estudio del Túmulo 2.

\subsection{Recinto 4}

Un lugar de interés al exterior del yacimiento es el Recinto 4. Se trata de un gran edificio de planta elíptica al servicio del programa ritual, pero no de uso funerario sino destinado probablemente a reuniones $\mathrm{y}$ rezos. Tiene $15 \times 7 \mathrm{~m}$, cuyo eje y puerta están orientados al nacimiento del sol en el solsticio de verano (Esteban y Benítez de Lugo, 20r6; Benítez de Lugo y Esteban, 20I8). Se localiza al este del Gran Túmulo I, independiente del mismo (figuras 4, 6 y 8). La puerta se encontró clausurada con barro y piedras. En su interior no se han encontrado enterramientos con conexión anatómica, aunque sí restos humanos dispersos en todos sus estratos formando parte del sedimento, así como material cerámico, óseo, lítico y metálico. Ver tabla I para material objeto de estudio del Recinto 4 .

\subsection{Cueva sepulcral}

En el interior de la cueva sepulcral, cuyo estudio y excavación comenzó en 20I2, la mayoría de los hallazgos presentados en este trabajo proceden de la Galería 2 (figuras 6 y 9 y tabla r). Se trata de la más amplia de las galerías subterráneas, con arte esquemático y numerosas evidencias de carácter funerario. En ella se encontraron restos de cerámica y fauna en abundancia. En la zona oeste de la Galería 2 destaca la presencia de un peine de alfarero o gradina (figura I2.3. $y$ figura 9.Io.) asociado a fragmentos cerámicos y gran acumulación de restos de microfauna y restos humanos. También se documenta material lítico.

En otro nivel de relleno de arcillas anaranjadas mezcladas con piedras de medio tamaño, probablemente derivadas de la erosión y parcial derrumbe del muro que separa las galerías i y 2 , cerca del acceso a la Galería 3, se documentaron un fragmento de punzón de hueso y un colgante (figura 15.3), asociados a abundantes restos de material cerámico, restos óseos 


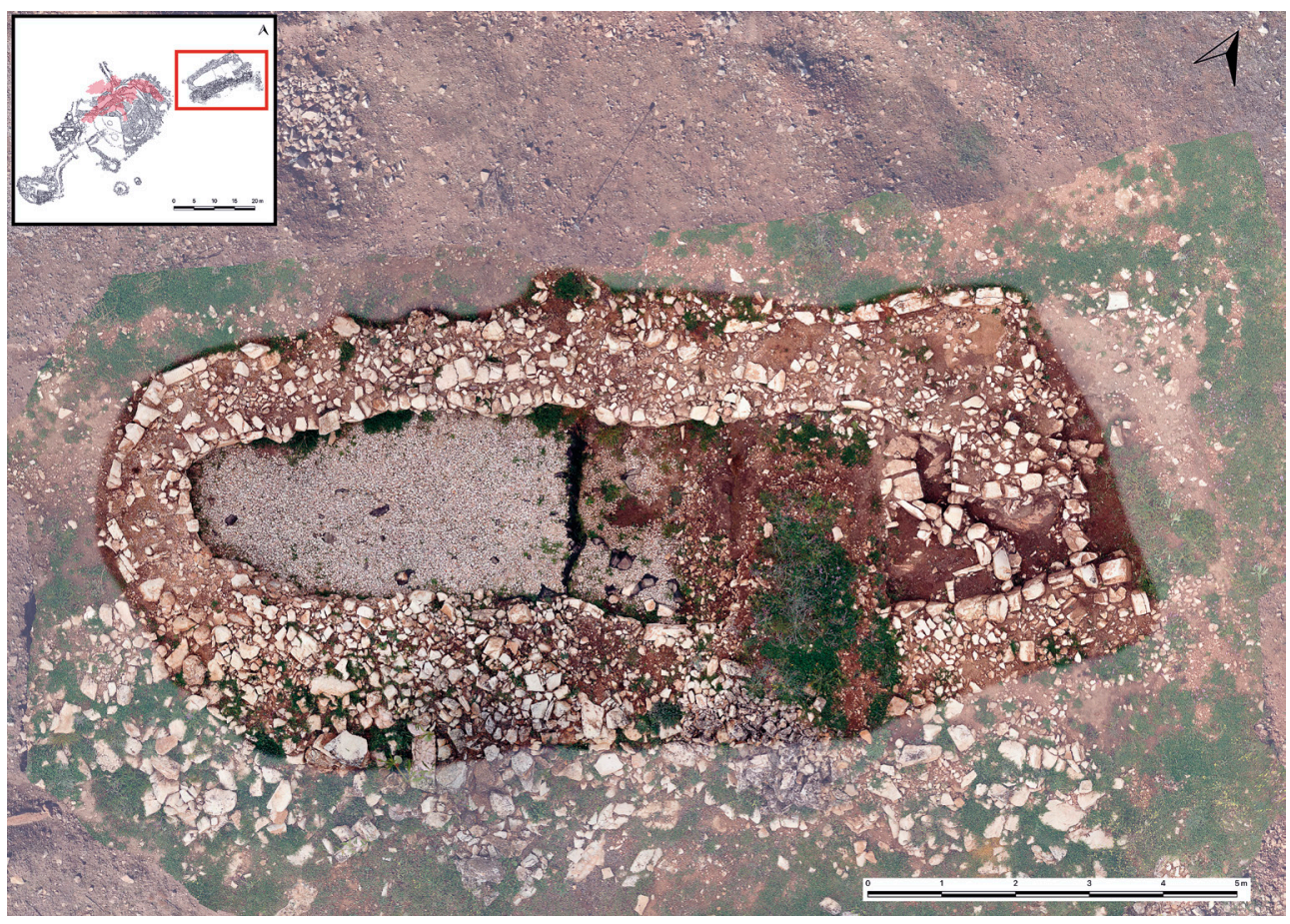

Figura 8. Recinto 4. Su entrada, a la derecha de la imagen, está orientada al solsticio de verano y se encontró clausurada con mampostería y barro

Figure 8. Enclosure 4. Its entrance, to the right of the image, is oriented to the summer solstice and it was found closed with masonry and clay

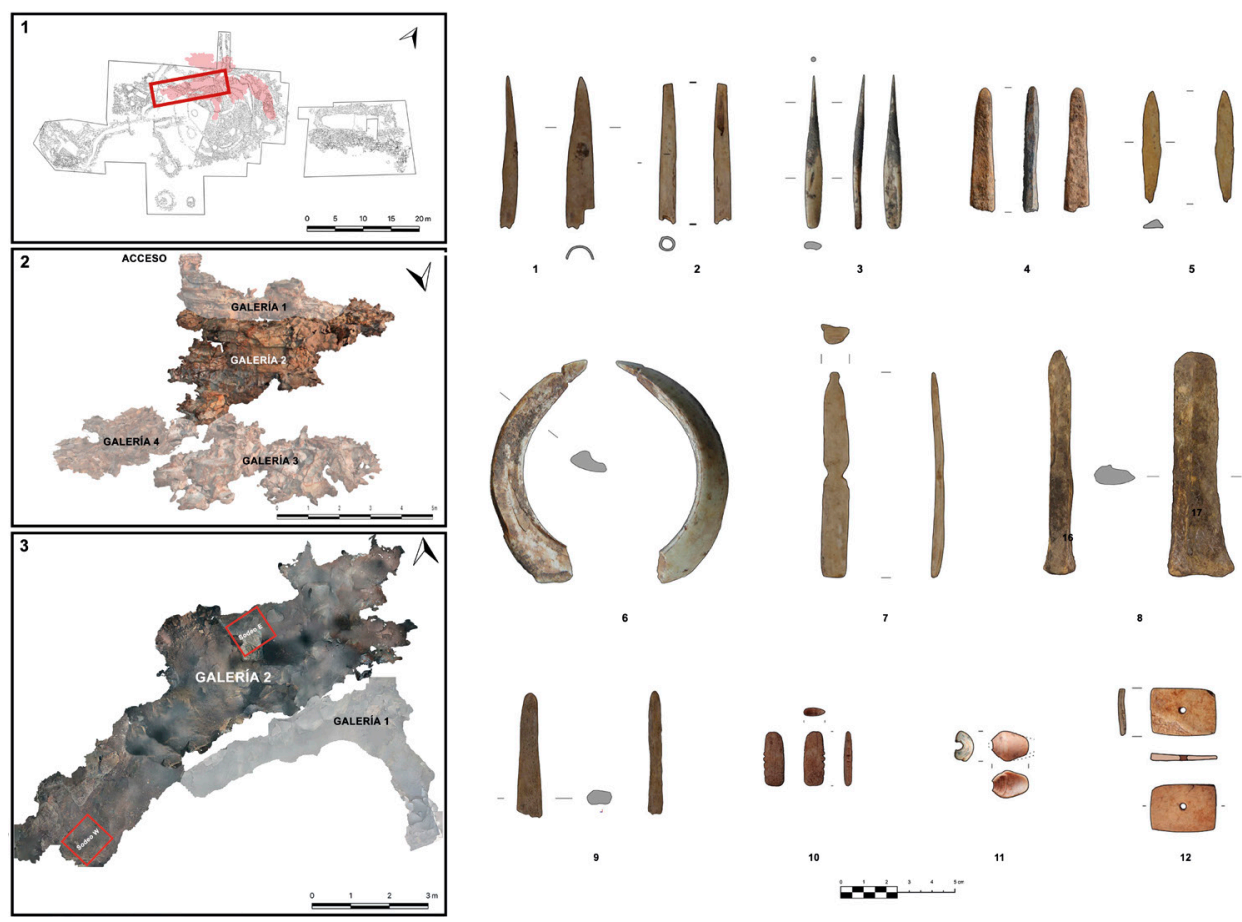

Figura 9. 1. Planta general del yacimiento, con la cueva marcada en rosa y la Galería 2 recuadrada en rojo. 2. Sección de la cueva sepulcral. 3. Planta de la Galería 2. 4. Industria ósea presentada en el texto recuperada de la Galería 2

Figure 9. 1. General plan of the site, with the cave marked in pink and Gallery 2 outlined in red. 2. Section of the sepulchral cave. 3. Floor plan of Gallery 2, locating Sounding E and Sounding W. 4. Bone industry presented in the text recovered from Gallery 2 


\begin{tabular}{|c|c|c|}
\hline NIVELES & & MATERIAL OBJETO DE ESTUDIO \\
\hline \multirow{30}{*}{ TÚMULO 1} & \multirow{2}{*}{ Sur } & TE15BOUE 223-1 \\
\hline & & TE15BOUE 234-1 \\
\hline & \multirow{2}{*}{ Oeste } & TE14BO/218-2 \\
\hline & & TE13BO/197-3 \\
\hline & \multirow{2}{*}{ Zona cenicienta } & TEo8/BO/F13/UE30 \\
\hline & & TE08/BO/D11/UE34 \\
\hline & \multirow{5}{*}{$\begin{array}{l}\text { Relleno túmulo } \\
\text { Zona Oeste }\end{array}$} & TE13BO/197-2 \\
\hline & & TE14BO/LIM.2 \\
\hline & & TE12BO/UE1/C7 \\
\hline & & $\mathrm{TE} 12 \mathrm{BO} / \mathrm{K} 5 / 1 / 1$ \\
\hline & & $\mathrm{TE} 12 \mathrm{BO} / \mathrm{BO} / \mathrm{UE} 1 / \mathrm{C} 7 / 2$ \\
\hline & Tumba 4 & TEO4BO \\
\hline & Tumba 5 & TE15BO255-2 \\
\hline & \multirow{14}{*}{ Galería 2} & $\mathrm{TE} 12 \mathrm{BO} / 26003 / 1$ \\
\hline & & TE12BO/26018-82 \\
\hline & & $\mathrm{TE} 12 \mathrm{BO} / 26006 / 7$ \\
\hline & & TE12/BO/SONDEO E/UE26006/44 \\
\hline & & TE12/BO/SONDEO/UE26007/PZ6 \\
\hline & & TE15BO/26010/2 \\
\hline & & TE15BOUE26013-19 \\
\hline & & TE15BO26013-78 \\
\hline & & TE15BO/26013-23, antes TE13BO/194-1 \\
\hline & & TE15BO/26013/75 \\
\hline & & $\mathrm{TE} 15 / \mathrm{BO} / 26024 / 1$ \\
\hline & & $\mathrm{TE} 15 \mathrm{BO} / 26013 / 19$ \\
\hline & & Micromamíferos \\
\hline & & Macrofauna \\
\hline & \multirow{3}{*}{ Galería 3} & TE12BO/UE26007/6 \\
\hline & & TE08BO/J7UE111 \\
\hline & & TE15BO26l10UE26013-21 \\
\hline \multirow{2}{*}{ Corredor 2} & & TE15BOUE 243-1 \\
\hline & & TE15BOUE 236-2 \\
\hline \multirow{2}{*}{ TÚMULO 2} & & TE12BOC122 UE84-2 \\
\hline & & TE12BO194-2 \\
\hline \multirow{6}{*}{ Recinto 4 (no funerario) } & & TE14BO/210-7 \\
\hline & & TE14BO/228-7 \\
\hline & & TE14BO/210-9 \\
\hline & & TE13BO/184-1 \\
\hline & & TE14BO/210-8 \\
\hline & & TE14BO/182-2 \\
\hline
\end{tabular}

Tabla 1. Correspondencia material arqueo-paleontológico con los niveles culturales del yacimiento

Table 1. Archaeo-paleontological material correspondence with the cultural levels of the site 
de fauna, así como restos humanos dispersos. Junto al acceso a la Galería 3 han aparecido un útil hendido, un punzón, un alisador-bruñidor, una cuenta de concha y un ídolo placa de hueso (figura 15.5). El contenido de este estrato es abundante, teniendo presencia de grandes fragmentos cerámicos, restos de fauna, y los restos humanos removidos. En la Galería I, de acceso a la cueva, se encontró en posición derivada un útil de hueso de base hendida. Fue localizado en el interior de un paleocanal arenoso que ha erosionado el estrato de relleno inferior de la Galería r. El material de las galerías 3 y 4 corresponde mayoritariamente a restos humanos y se encuentra pendiente de estudio.

\section{Material y métodos}

Los restos de micromamíferos proceden del lavado y tamizado de los sedimentos recuperados en el Sondeo W de la Galería 2 durante la campaña de 20I2. Para ello, se utilizó una pila de tamices con luces de malla decrecientes de Io, 5, 3, I y o,5 mm. Los residuos resultantes fueron triados a simple vista en el caso de las fracciones de $3 \mathrm{~mm}$ o superiores, o con la ayuda de una lupa binocular en el caso de las fracciones más finas. La identificación de los restos se llevó a cabo mediante su comparación con colecciones de micromamíferos actuales procedentes de egagrópilas, y mediante el uso de distintos atlas y obras de referencia (Féderation des Clubs CPN, 20I0; Román, 2019).

Un total de 196r restos faunísticos de las campañas de excavación de 2003-2004 han sido analizados por Eva Orri Terrado (Orri, 2004). Por otra parte, la doctora $M^{a}$. Ángeles Galindo Pellicena ha realizado el estudio de los restos faunísticos utilizados para realizar los útiles óseos de las campañas de 20I2-2015; el resto de la fauna está pendiente de estudio. Amalia Pérez-Romero ha realizado el análisis tipológico de las 32 piezas de industria ósea identificadas en el Bronce de Castillejo de Bonete (ver tabla I para procedencia). Ángel C. Domínguez García,la doctora Paloma Sevilla y el doctor César Laplana han estudiado los micromamíferos recuperados en el Sondeo W de la Galería 2 de la cueva sepulcral en 20 I2.
En relación con el estudio de los macromamíferos, se ha realizado el análisis anatómico y taxonómico a partir de colecciones de referencia de esqueletos de animales actuales del Centro UCM-ISCIII de Evolución y Comportamiento Humanos y atlas de anatomía animal (Pales y Lambert, 1971; Schmid, 1972; Barone, 1999; Pales y García, 198I). En los casos en que ha sido posible hemos diferenciado entre Ovis aries y Capra hircus, utilizando la guía de Boessneck (1969).

Se ha cuantificado los restos faunísticos separándolos en restos identificados (NISP) y restos no identificados. Hemos calculado el NMI (Número Mínimo de Individuos) teniendo en cuenta la lateralidad y la edad de los individuos (Klein y Uribe, 1984). Se ha intentado remontar las piezas, pero el nivel de fracturación no permite resultados fiables.

Hemos determinado la edad de sacrificio a partir del grado de osificación de los huesos y la erupción y desgaste dental, de acuerdo con Silver (I980).

La extracción del colágeno para las dataciones y el análisis de los indicadores de calidad del mismo se realizaron directamente en los laboratorios isotópicos del MPI-EVA (Leipzig, Alemania) siguiendo el protocolo descrito en Salazar-García et alii (2014). Los parámetros fueron todos aceptables, tras lo cual se enviaron al Poznan Radiocarbon Laboratory ( $\mathrm{Poz}^{-}$ nan, Polonia) para el análisis de radiocarbono.

En relación con la industria ósea se ha realizado un estudio morfológico del material y de la materia prima que se ha utilizado, a partir de la identificación anatómica del elemento esquelético y la identificación taxonómica al máximo nivel posible. También se ha investigado sobre paralelos en otros yacimientos de similar cronología.

\section{Resultados}

\subsection{Micromamíferos}

Castillejo del Bonete destaca por su registro arqueoecológico, debido a la riqueza, tanto en número de restos como de taxones, de sus asociaciones de microvertebrados. La mayor parte de este material estudiado procede del interior de la cueva, en concreto del Sondeo W practicado en la Galería 2 (figura 9.3), donde se han 


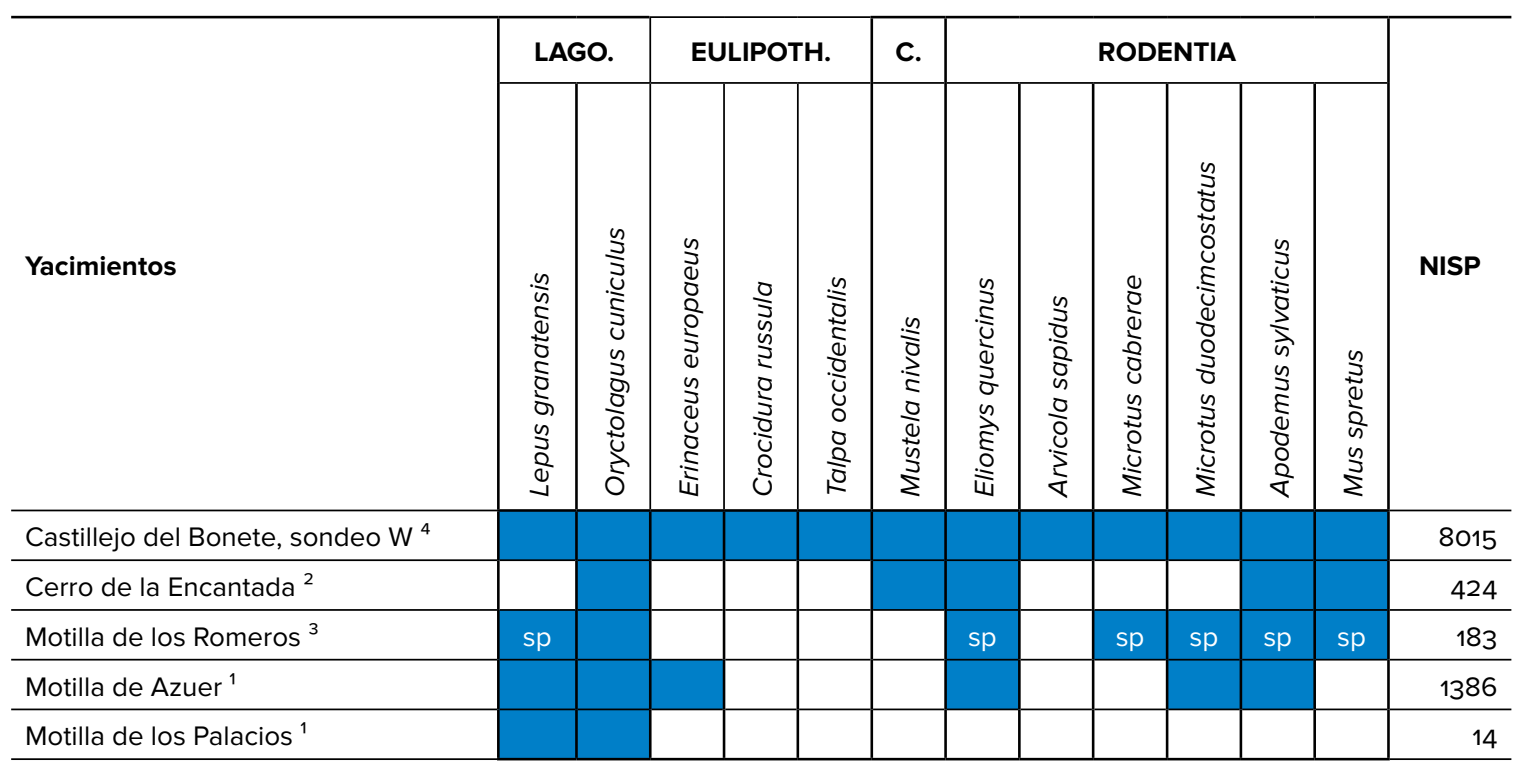

Tabla 2. Síntesis del registro de micromamíferos de diferentes yacimientos de la Edad del Bronce de la provincia de Ciudad Real. Identificaciones de: (1) Von Den Driesch y Boessneck (1980), (2) Morales Muñiz (1986), (3) Morales Muñiz et alii (1987), (4) Domínguez García et alii (2019a) y este trabajo. Abreviaturas: Lago.: Orden Lagomorpha, Eulipoth.: Orden Eulipotyphla; C.: Orden Carnivora; sondeo W: sondeo oeste; NISP: número de elementos identificados

Table 2. Synthesis of the record of small mammals from different Bronze Age sites in the province of Ciudad Real province. Identifications from: (1) Von Den Driesch and Boessneck (1980), (2) Morales Muñiz (1986), (3) Morales Muñiz et alii (1987), (4) Domínguez García et alii (2019a) and this work. Abbreviations: Lago.: Order Lagomorpha, Eulipoth.: Order Eulipotyphla; C.: Order Carnivora; sounding W: west probe; NISP: number of elements identified

recuperado varias decenas de miles de restos de micromamíferos, anfibios, reptiles y aves (Benítez de Lugo et alii, or5b; Domínguez-García et alii, 2019). Hasta el momento solo los restos de micromamíferos han sido estudiados en profundidad (Domínguez-García et alii, 2019a), habiéndose identificado un total de 80I4 restos pertenecientes a II especies distintas. En este punto de la investigación es posible afirmar ya que se trata, con seguridad, del registro más completo de estos grupos de vertebrados del sur de la península ibérica durante la Edad del Bronce. A modo de ejemplo, en la tabla 2 se han comparado los listados de especies de micromamíferos del Sondeo W de Castillejo del Bonete con otros yacimientos del Bronce de La Mancha. En ella se aprecia que el listado de especies de este yacimiento es el más completo de todos y el número de restos identificado es mucho mayor que en cualquier otro. Hay que tener en cuenta además que para el cálculo del número de restos en Castillejo del Bonete se han utilizado principalmente los restos dentarios, mientras que en los demás yacimientos se han contabilizado también los restos óseos (tabla 2). En este trabajo se añade la presencia de otra especie, la comadreja (Mustela nivalis), representada por un único resto.
La extraordinaria concentración de restos de microvertebrados tiene su origen en la utilización de un sector de la cueva como madriguera y letrina por parte de uno o varios carnívoros. La acumulación de excrementos - de los que se han conservado algunos en forma de coprolitos- $y$ su descomposición produjeron la incorporación a los sedimentos de la cueva de grandes cantidades de huesos correspondientes a las presas ingeridas por este carnívoro, cuya Galería 2 utilizaba como madriguera en una de sus cotas superiores, una vez quedó en desuso por las comunidades del Bronce. Debido a este contexto, la gran mayoría de los restos dentarios y óseos muestran abundantes evidencias de ataque ácido producidas durante el $\mathrm{pa}^{-}$ so de los mismos por el tracto digestivo del predador, y una gran fracturación a consecuencia de haber sido masticados previamente a su ingestión. El tamaño de las presas presentes en el yacimiento indican que el carnívoro que ocupó la cueva tuvo que ser de talla media o pequeña, acorde al de las presas consumidas (pequeño cánido, pequeño félido, mustélido). Realizar una inferencia específica del depredador que produjo la acumulación de restos de microvertebrados resulta muy complicado, debido a la escasez de criterios 


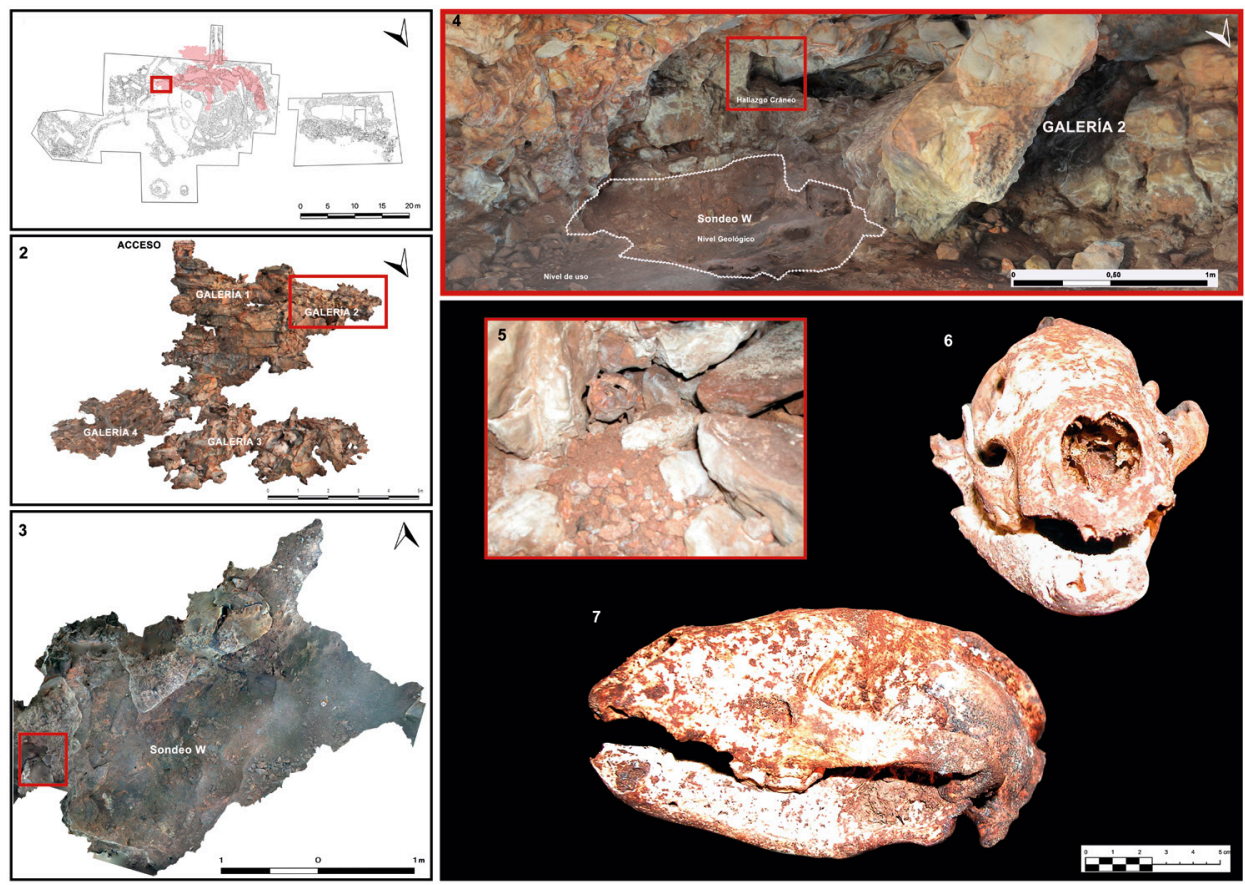

Figura 10. Tejón prehistórico muerto en el extremo Este de la Galería 2, convertida en su madriguera cuando el lugar cayó en desuso por las comunidades de la Edad del Bronce

Figure 10. Prehistoric badger dead in the east corner of Gallery 2, converted into its burrow when this site fell into disuse by Bronze Age communities

uniformes que permitan discriminar entre distintas especies de pequeños mamíferos (Domínguez García et alii, 2orgb). No obstante, además de la presencia de comadreja, un cráneo y otros restos óseos de tejón (Meles meles) fueron encontrados en este lugar en el momento del descubrimiento de la cueva en 2004 (figura Io). El espectro de especies identificadas se encuentra dentro del rango de presas consumidas por ambas especies (Virgós et alii, 2005; Barea-Azcón et alii, 2010; Palazón, 20I2). Por ello, se puede plantear la hipótesis de que la comadreja, el tejón, o ambos, fuesen los agentes productores de la concentración de restos de microvertebados. Para confirmar esta hipótesis y precisar la asignación específica será necesario un análisis tafonómico detallado de los restos y su comparación con acumulaciones de vertebrados actuales producidas por estos mustélidos y otros mamíferos carnívoros.

\subsection{Macromamíferos}

Los restos de macromamíferos estudiados constituyen un total de I 916, de los cuales 729 restos (38,04\%) se han identificado anatómica y taxonómicamente y II84 $(61,96 \%)$ son incluidos como restos no identificados.
El ganado ovicaprino (Ovis aries/Capra hircus) es el mejor representado con $196(67,58 \%$ del total de restos identificados) y un NMI de 57 , seguido de Bos taurus con 49 (16,9 \%): NMI = 19; Sus domesticus con 34 (II,72 \%): NMI = 20; Canis familiaris con 9 restos (3,I \%): NMI $=4$. También están representados animales salvajes como: Cervus elaphus con I resto (o,34 \%). Hemos identificado I resto de ave (o,34 \%) (ver tabla 3).

El perfil de mortalidad del ganado ovicaprino sugiere una explotación mixta, con un 64,15\% de individuos sacrificados con una edad por encima de los 4 años (adultos) y un 35,85\% con menos de 4, entre infantiles y subadultos. Ello indica una explotación enfocada a la obtención de carne y leche, y el alto porcentaje de individuos adultos sugiere un mantenimiento del ganado y la obtención de productos secundarios, como la lana. El perfil de mortalidad del ganado bovino también sugiere una explotación mixta, enfocada a la obtención de leche y carne, con el sacrificio minoritario de individuos infantiles y subadultos (II,II \%) e individuos adultos $(88,89 \%)$. Sin embargo, el alto porcentaje de individuos adultos lleva a pensar en una explotación 


\begin{tabular}{lcccc}
\hline & NISP & \%NISP & NMI & \%NMI \\
\hline Total Ovis aries/Capra hircus & 196 & 67,59 & 57 & 55,88 \\
\hline Bos taurus & 49 & 16,90 & 19 & 18,63 \\
\hline Sus domesticus & 34 & 11,72 & 20 & 19,61 \\
\hline Cervus elaphus & 1 & 0,34 & 1 & 0,98 \\
\hline Canis familiaris & 9 & 3,10 & 4 & 3,92 \\
\hline Ave indet. & 1 & 0,34 & 1 & 0,98 \\
\hline TOTAL & $\mathbf{2 9 0}$ & $\mathbf{1 0 2}$ & \\
\hline
\end{tabular}

Tabla 3. NISP (Número de Restos Identificados) y NMI (Número Mínimo de Individuos) con sus frecuencias. Tomado de Orri Terrado (2004)

Table 3. NISP (Number of Identifiable Remains) and NMI (Minimum Number of Individuals) with their relative frequencies. Taken from Orri Terrado (2004)

enfocada principalmente a la reproducción del ganado, en el caso de las hembras, y a la utilización del ganado como animales de carga y tiro. El perfil de mortalidad de los cerdos, en el que se sacrifican individuos subadultos $(38,89 \%)$ e individuos adultos $(6 \mathrm{I}, \mathrm{II} \%)$ indica una explotación mixta con individuos más jóvenes para el consumo (con su óptimo cárnico) y con un mayor porcentaje de individuos de edad más avanzada, enfocada al mantenimiento del ganado con la reproducción de la especie (ver tablas 4-6).

Otras evidencias significativas encontradas son los artrópodos que parasitaban la funda de piel (de probable cabra) en la cual estaba envainada el cuchillo de cobre con un remache encontrado junto a la cadera del Individuo 2 (masculino) de la Tumba 4 (Benítez de Lugo et alii, 20I5b: I2I).

\subsection{Industria sobre materia dura de origen animal}

A partir de los restos óseos de estos animales identificados se han encontrado útiles con diferentes funciones.

La industria ósea de Castillejo de Bonete está constituida por 40 piezas completas o casi completas elaboradas en materia dura de origen animal (hueso, asta, dientes), que fueron utilizadas como medios de producción (útiles), complementos para el vestido y ornamentos (adornos) e ídolos. Dos de estas piezas son matrices (dado el trabajo previo realizado en ellas no se ha podido determinar a qué animal pertenecen, ni si se trata de un desecho de producción) (Averbouh y Provenzano, 1998-I999). A estos se le añade un elemento malacológico de origen marino. No se incluyen en este trabajo los huesos con marcas de carnicería ni aquellos que presenten superficies alteradas por procesos postdeposicionales (mordisqueos, procesos físicos y químicos).

La elección de la materia prima de origen animal para la elaboración de estos objetos dependía no solo de la función prevista para el objeto final - los huesos tubulares eran destinados principalmente para realizar punzones, agujas, alfileres, etc., mientras que los aplanados resultaban más aptos para espátulas, alisadores, etc. - sino que la elección en términos de especie y elemento esquelético para fabricar herramientas está tan relacionada con la tradición como la eficacia de la forma del elemento esquelético para la función prevista de la herramienta. En otras palabras, la costumbre, la creencia y la practicidad no tienen por qué ser aspectos mutuamente excluyentes de la selección de materias primas (Choyke y Bartosiewicz, 2009). Además, hay que tener en cuenta que algunas piezas anatómicas despiertan la imaginación de individuos, por esto no deja de ser llamativa la fabricación, por ejemplo, de cabezas de caballo a partir de falanges durante el magdaleniense, recordando en cierta manera al aprovechamiento que se les da a algunos hioides; o la de los ídolos sobre hueso (falanges, metapodio, etc.) en las culturas con cerámica (Mujika Alustiza, 2007-2008.)

Como materia prima de estos elementos seleccionados se ha observado un predominio de diferentes partes del endoesqueleto: de las 40 piezas de industria ósea analizadas 39 están elaboradas con 


\begin{tabular}{|c|c|c|c|c|c|}
\hline & Infantil & Infantil/Subadulto & Subadulto & Adulto & Indet. \\
\hline Ovis aries/Capra hircus & 8 & & 11 & 29 & 4 \\
\hline Capra hircus & & & & 5 & \\
\hline Total OC & 8 & & 11 & 34 & 4 \\
\hline Bos taurus & 1 & 1 & & 16 & 1 \\
\hline Sus domesticus & & & 7 & 11 & 2 \\
\hline Cervus elaphus & & & & 1 & \\
\hline Canis familiaris & & & & 4 & \\
\hline Ave indet. & & & & & 1 \\
\hline TOTAL & 11 & 1 & 18 & 134 & 8 \\
\hline
\end{tabular}

Tabla 4. NMI de cada especie por edad de sacrificio: infantil; infantil/subadulto; subadulto; adulto e indet. (indeterminados). Datos tomados de Orri Terrado (2004)

Table 4. NMI of each species by slaughter age: infant; infant/subadult; subadult; adult and indet. (indeterminate). Data taken from Orri Terrado (2004)

\begin{tabular}{lcccc}
\hline & Infantil & Inf-Subad & Subadulto & Adulto \\
\hline Ovis aries/Capra hircus & 15,09 & 0,00 & 20,75 & 64,15 \\
\hline Bos taurus & 5,56 & 5,56 & 0,00 & 88,89 \\
\hline Sus domesticus & 0,00 & 0,00 & 38,89 & 61,11 \\
\hline
\end{tabular}

Tabla 5. Frecuencia relativa de los individuos de la tríada doméstica, separados por edad de sacrificio. Total OC (total ovicaprinos)

Table 5. Relative frequency of the individuals of the domestic triad, separated by slaughter age. Total OC (total ovicaprines)

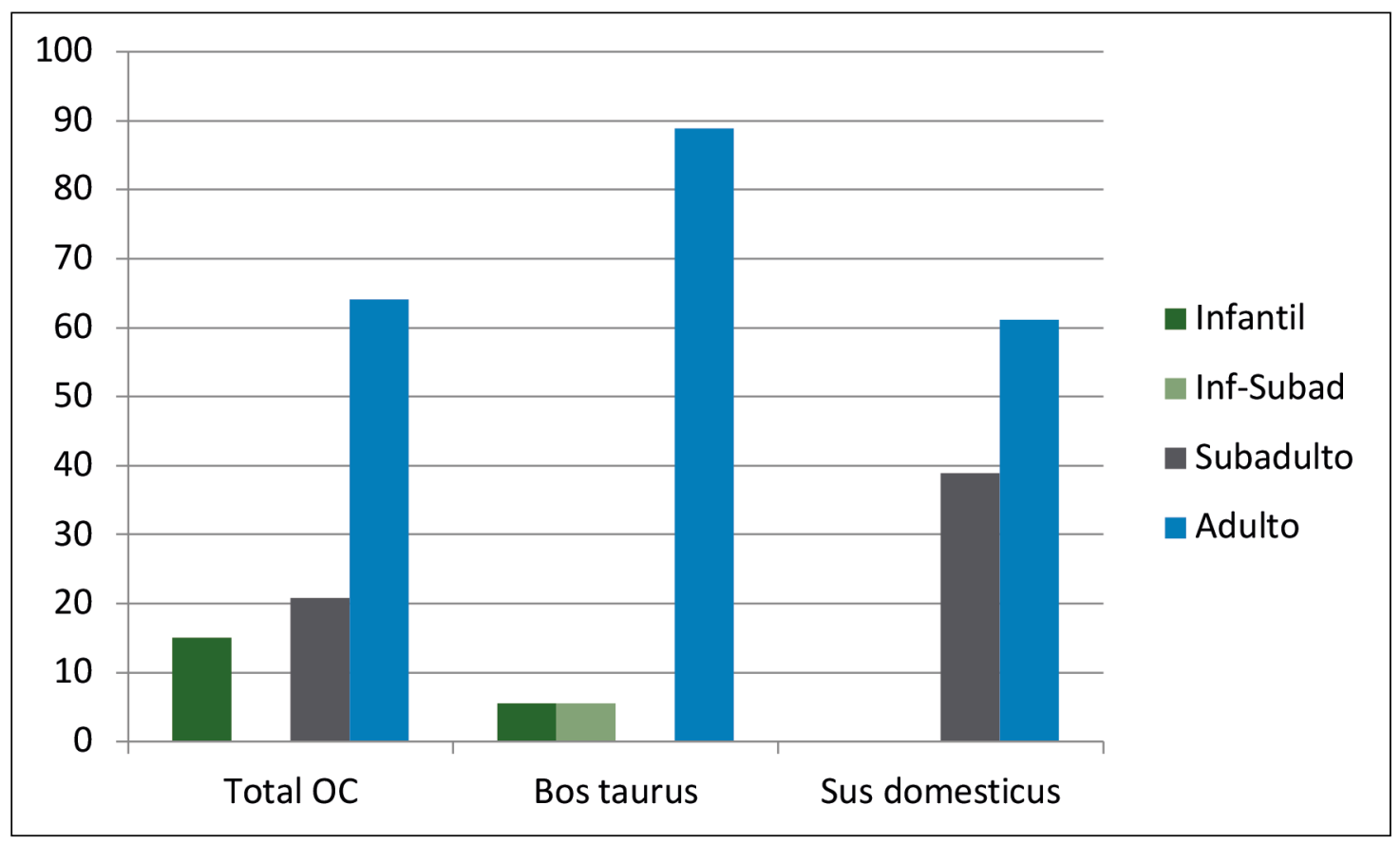

Tabla 6. Perfil de mortalidad de la tríada doméstica (ovicaprinos: OC; Bos taurus y Sus domesticus), calculado a partir de la osificación de los huesos y erupción y desgaste dental

Table 6. Mortality profile of the domestic triad (ovicaprines: OC; Bos taurus and Sus domesticus), calculated from ossification of bones and tooth eruption and wear 
elementos anatómicos del esqueleto de animales (89,74 \% sobre hueso y 7,70 \% sobre piezas dentarias), tanto salvajes como domésticos. Tan solo una se elaboró en concha (Collumbellidae) (2,56\%) (tabla 7).

Se han identificado 20 útiles (51,28\%), ig elementos de adorno ( $46,16 \%)$ y un posible ídolo $(2,56 \%)$. Como soporte de las herramientas se utilizaron elementos óseos mayoritariamente pertenecientes al esqueleto apendicular (metapodios, tibias, húmeros, radios, huesos largos), huesos planos (escápulas, costillas), dientes y astas (en el caso de los cérvidos) o cuernos (en el caso de los bóvidos). La identificación taxonómica de los soportes resulta complicada, debido a las alteraciones en el proceso de su fabricación y a su uso posterior. A pesar de ello, se han podido identificar $20(64,5 \%)$ de los 3I soportes óseos utilizados para la realización de la industria de Castillejo de Bonete. Los animales identificados utilizados como soporte son: 8 mamíferos de talla

\subsubsection{Tipologías}

\section{a) Útiles (tabla 7)}

\section{a1) Apuntados}

Los punzones de hueso (al igual que los de cobre) son especialmente numerosos (figura 11). Estos objetos han sido elaborados sobre hueso, asta y diente. Al igual que las agujas pudieron utilizarse en la producción textil y en la cestería para tejer, coser o perforar piezas de lino y esparto, a juzgar por evidencias contextuales recogidas en varios asentamientos coetáneos por toda la península ibérica. Atendiendo a caracteres morfotécnicos cabe distinguir varios tipos:

Biapuntados: TE12BO/26003/1 (84 mm $\times 8 \mathrm{~mm} \times 6 \mathrm{~mm})$ y TE14BO/210.3 (29 mm $\times 3 \mathrm{~mm} \times 3 \mathrm{~mm}$ ) (figURAS 11.1 y 11.2).

Hendidos. Obtenidos a partir de la diáfisis de los huesos largos. Presentan los bordes del fuste paralelos o suavemente convergentes y la cara ventral alisada. Dentro de esta tipología se ha podido diferenciar entre:

- Hendidos: TE13BO/197.3 (30 mm × $5 \mathrm{~mm} \times 3 \mathrm{~mm}$ ); TE15BO UE223.1 (35,5 mm × $5 \mathrm{~mm} \times 2 \mathrm{~mm}$ ); TE15BO 26l1024 UE2613.21 (52 mm $\times 13 \mathrm{~mm} \times 3 \mathrm{~mm}$ ) (figuras 11.3, 11.4 y 11.5).

- Hendidos sobre base articular: TE13BO/184.1 (155 mm × $21 \mathrm{~mm} \times$ $14 \mathrm{~mm}$ ); TE14BO/210.7 (95 mm × $14 \mathrm{~mm} \times 3 \mathrm{~mm}$ ); TE14BO/228.7 $(71 \mathrm{~mm} \times 17 \mathrm{~mm} \times 15 \mathrm{~mm}) ; \mathrm{TE} 15 \mathrm{BO} / 234.1(78 \mathrm{~mm} \times 12 \mathrm{~mm} \times 5 \mathrm{~mm}) \mathrm{y}$ TE13BO/26007/6 (67 mm $\times 8 \mathrm{~mm} \times 3 \mathrm{~mm}$ ) (figuras 11.6 a 11.10).

- Hendidos sin base (2): TE15BO/26024.I (99 mm × 27 mm × $12 \mathrm{~mm}$ )y TE14BO/218.2 (92 mm × $16 \mathrm{~mm} \times 7,5 \mathrm{~mm}$ ) (figuras $11.11 \mathrm{y} 11.12)$.

- Tubular sin base: encajamos aquí un elemento incompleto: TE15BO UE $2613 \mathrm{Pz} 190$ (66 mm × $11 \mathrm{~mm} \times 8 \mathrm{~mm}$ ) (figura 11.13).

De economía: integra a fragmentos y esquirlas con acondicionamiento exclusivo de la punta conformando cuerpos irregulares.TE14BO/219/9 (49 mm × $9 \mathrm{~mm} \times 5 \mathrm{~mm}$ ) (figura 11.14). media (talla ovicaprino: $40 \%$ ); 5 cérvidos ( $25 \%$ ), fundamentalmente Cervus elaphus; 4 ovicaprinos (20\%); I Sus scrofa (5\%); i Bos taurus (5\%) y i Lepus sp. (5\%). La representación de estas especies sugiere un tipo de aprovechamiento animal basado tanto en el consumo y utilización de animales salvajes como domésticos.

Las astas de cérvido estudiadas sirvieron sin duda para fabricar instrumental, ya que se trata de piezas muy poco elaboradas, con un leve agudizamiento distal de los candiles (figuras ir.I y i2.6).

La presencia restos óseos exógenos, como es el marfil utilizado para la fabricación de algunos botones, que podría haber llegado de desde el Mediterráneo oriental o la presencia de conchas marinas, está hablando de intercambios comerciales a larga distancia. Esta evidencia ya ha sido documentada en Castillejo del Bonete con anterioridad (Benítez de Lugo et alii, 20I5a; Odriozola et alii, 2016).
Facetado: TE12BO/26006/7 (52 mm × $11 \mathrm{~mm} \times 6 \mathrm{~mm}$ ) (figura 11.15).

Punta de flecha (posible tipo Palmela): elaborada a partir de diáfisis de hueso largo indeterminado: TE12BO UE236-2 (39 mm $\times 9 \mathrm{~mm} \times 2 \mathrm{~mm}$ ) (figura 12.1).

\section{a2) Espatulados}

Alisador/bruñidor: se trata de una pieza realizada sobre diáfisis de hueso largo, hendida redondeada y pulida en su parte activa. El uso que se propone para este tipo de útiles está relacionado con su participación en actividades de peletería y curtiduría debido al intenso pulido que muestran sus superficies. En Castillejo del Bonete contamos con la presencia de un solo ejemplar: TE15BO/26013.78 (95 mm × 55 mm × 9 mm) (figura 12.2)

Peine de alfarero o gradina: útil cuyo extremo distal es ligeramente curvo, apareciendo dentado en uno de sus perfiles laterales. El fuste es de sección aplanada y su extremo proximal variable: TE12BO/26018/P82 (52 mm × $7 \mathrm{~mm} \times 3,5 \mathrm{~mm}$ ) (figura 12.3).

Picos: realizados sobre asta, sin apenas elaboración ya que tan solo presentan un leve aguzamiento distal. No se sabe con certeza cuál era el uso de estas piezas. TE15BO/255-2 (76 mm × 4,5 $\mathrm{mm} \times 9 \mathrm{~mm}) ; \mathrm{TE} 12 \mathrm{BO} / 26006 / 7(74 \mathrm{~mm} \times 5 \mathrm{~mm} \times 9 \mathrm{~mm}) ;$ $\mathrm{TE} 14 \mathrm{BO} / 210.8(72 \mathrm{~mm} \times 26 \mathrm{~mm} \times 19 \mathrm{~mm})$ (figuras $12.4,12.5$ y 12.6).

\section{b) Elementos de adorno (figura 13 y Tabla 7)}

Cuentas: dentro de este grupo se ha podido diferenciar entre:

- Cuentas discoidales. Conforman un grupo muy homogéneo formado por siete pequeñas cuentas de las que ha sido imposible determinar el tipo de hueso dado el alto grado 

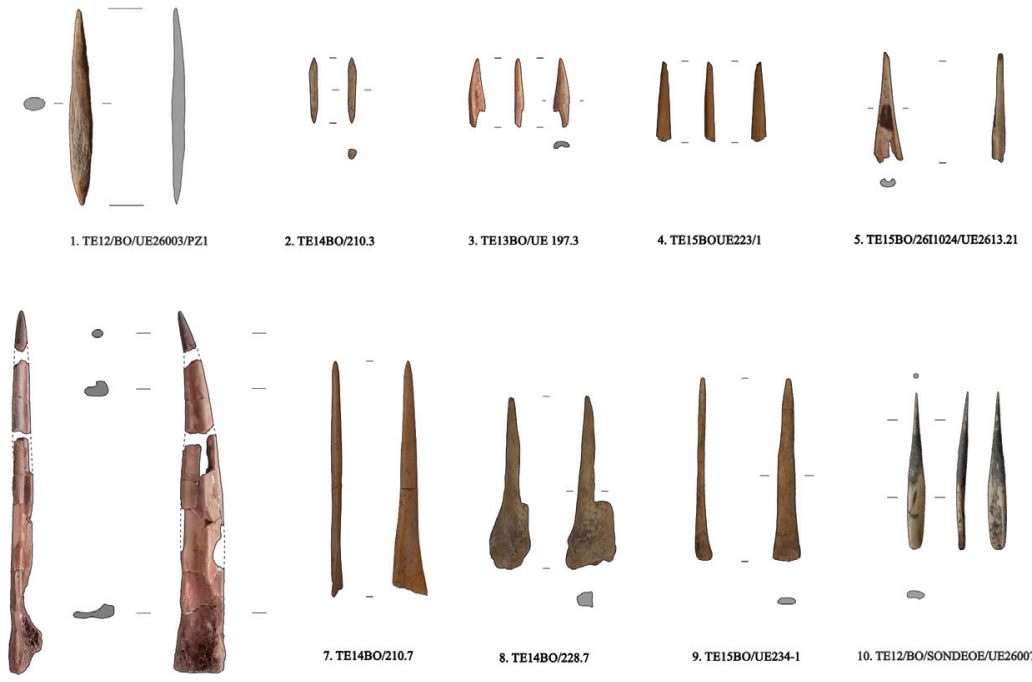

7. TE14B0/210.7

8. TE14BO2228.7

9. TE15BO/UE234-1
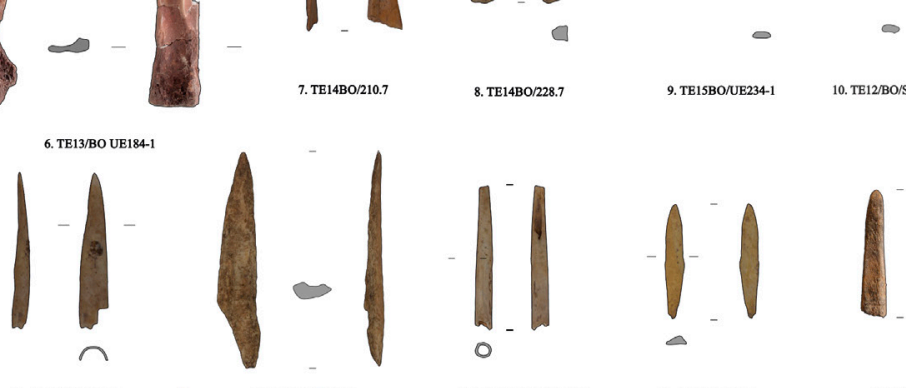

$\int_{-}^{-}$
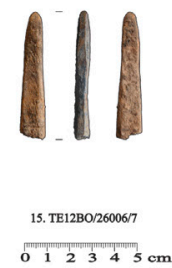

Figura 11. Punzones

Figure 11. Punches

de transformación y el reducido tamaño de los artefactos: TE12BO/K5/1/1 ( $\varnothing$ máximo: 3,5 mm; Grosor máximo: 1 mm; $\varnothing$ perforación: 1,5 mm);TE12BO/UE1/C7 ( $\varnothing$ máximo: $9 \mathrm{~mm}$; Grosor máximo: $1,5 \mathrm{~mm}$; $\varnothing$ perforación: 1,5 mm); TE13BO/ K5/1/1 ( $\varnothing$ máximo: 5 mm; Grosor máximo: 1,5 mm; $\varnothing$ perforación: 0,8 mm); TE13BO/197.2 (Ø máximo: 4 mm; Grosor máximo: 3,5 mm; $\varnothing$ perforación: 1,5 mm); TE14BO/LIM.2 ( máximo: 4,5 mm; Grosor máximo: $4,5 \mathrm{~mm}$; $\varnothing$ perforación: 1 mm); TE14BO/182.2 (Ø máximo: 4 mm; Grosor máximo: 4 mm; $\varnothing$ perforación: $1 \mathrm{~mm}$ ) (figuras 13.1 a 13.5).

- Una cuenta realizada sobre un gasterópodo (Collumbellidae) TE15BO/26013-19 (18 mm × $14 \mathrm{~mm} \times 5 \mathrm{~mm}$ ) (figura 13.7), pulido por desgaste en sus dos caras. Prácticamente no conserva ninguna estructura externa ni interna, llegando incluso hasta haber desaparecido la columela (Benítez de Lugo et alii, 2015).

- Cuenta/botón: TE12BO/26010/2 $(29 \mathrm{~mm} \times 19 \mathrm{~mm} \times 2,5 \mathrm{~mm}$. $\varnothing$ perforación: $2 \mathrm{~mm}$ ) (figura 13.8).

Botones con perforación en V (figura 10): Contamos con seis piezas, de tipología piramidal de base ligeramente rectangular, con dos perforaciones en la base que se cortan formando una V. Estas piezas presentan tanto en su superficie como en las perforaciones realizadas en ellas un lustre especial resultado del uso de las piezas al estar cosidas (con fibras vegetales trenzadas compatibles con esparto) sobre una tela. Estos botones, constituyen un artículo de amplia distribución geográfica a lo largo del III y II milenio BC. Mayoritariamente presentan forma piramidal: TE15BO/UE243.1 (14 mm × $10 \mathrm{~mm} \times 1 \mathrm{~mm}$ ); TEO4BO Tumba 4 Ind $1(45 \mathrm{~mm} \times 23 \mathrm{~mm} \times 12 \mathrm{~mm})$; TEO 4 BO Tumba 4 Ind $1(43 \mathrm{~mm} \times 22 \mathrm{~mm} \times 0,9 \mathrm{~mm}$ ); TE12BO C12 UE84-2 (anchura 30 $\mathrm{mm}$ ); TE12BO194-2 (40, $\mathrm{mm} \times 22 \mathrm{~mm} \times 6 \mathrm{~mm}$ ) (figuras $14.1 \mathrm{a} 14.5)$.

\section{Colgantes}

- Un colgante realizado con un canino inferior de suido. Este es un recurso ampliamente constatado para la elaboración de elementos de adorno personal durante el III y II milenio cal BC en la península ibérica (Fonseca, 1984-1985; Altamirano, 2011): TE12BO/SONDEOE/UE26006/44 (102 mm × $15 \mathrm{~mm} \times 8 \mathrm{~mm}$ ) (figura 15.1).

- Otros dos sobre piezas dentarias: TE08BO/F13/UE30 $(25 \mathrm{~mm} \times 6 \mathrm{~mm} \times 2 \mathrm{~mm}) ;$ TEO8BO/J7UE $111(37 \mathrm{~mm} \times 5 \mathrm{~mm} \times 5 \mathrm{~mm})$ (figsuras 15.2 y 15.3).

- El último sobre hueso indeterminado: TE05BO/D11UE34 (35 mm $\times 7 \mathrm{~mm} \times 3 \mathrm{~mm}$ ) (figura 15.4).

\section{c) Ídolo/lamina con escotaduras. Tabla 7}

Posible placa idoloforme plana de hueso con dos pares de escotaduras. Posiblemente en proceso de fabricación. Esta pieza fue hallada al final de la Galería 2 de la cueva, junto al acceso a la Galería 4: TE15BO/UE26013/23 (88 mm × $11 \mathrm{~mm} \times 3,5 \mathrm{~mm}$ ) (figura 15.5). 


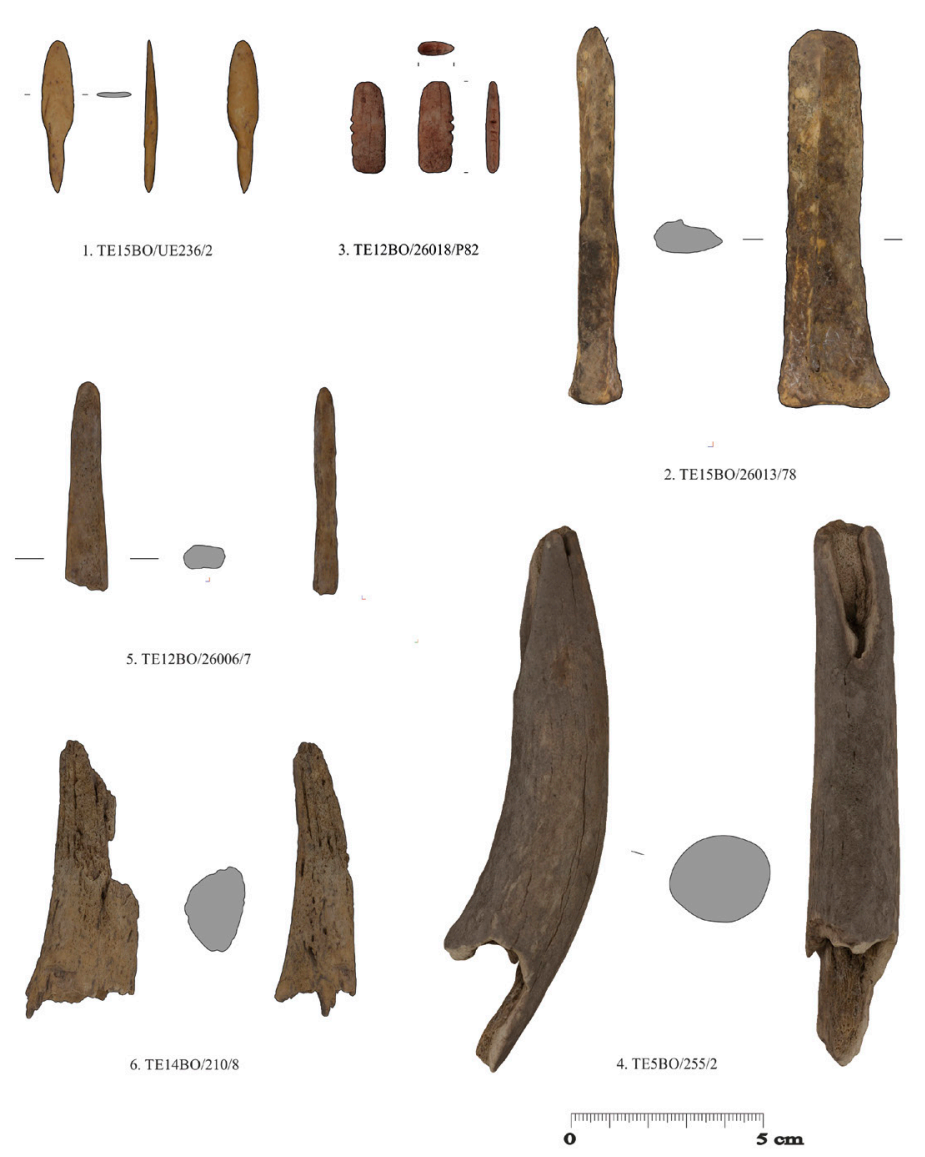

Figura 12. Útiles

Figure 12. Tools

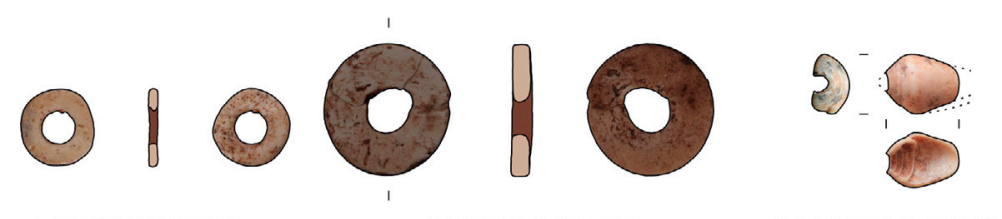

1. TE12BO/ K5/1/1

2. TE12BO/UE1C7

7. TE15BO/26013-19
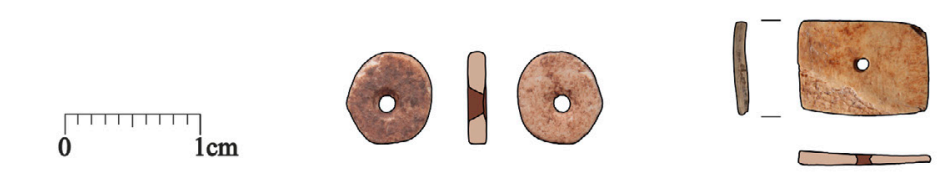

3. TE13BO K5/UE1/1
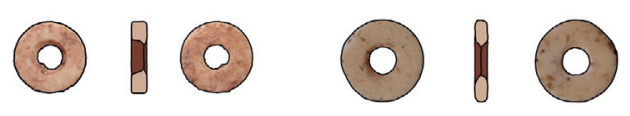

8. TE12BO/26010/2

4. TE13BO/UE 197-2

5. TE14BO/LIM-2

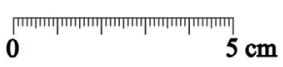

Figura 13. Adornos

Figure 13. Ornaments 


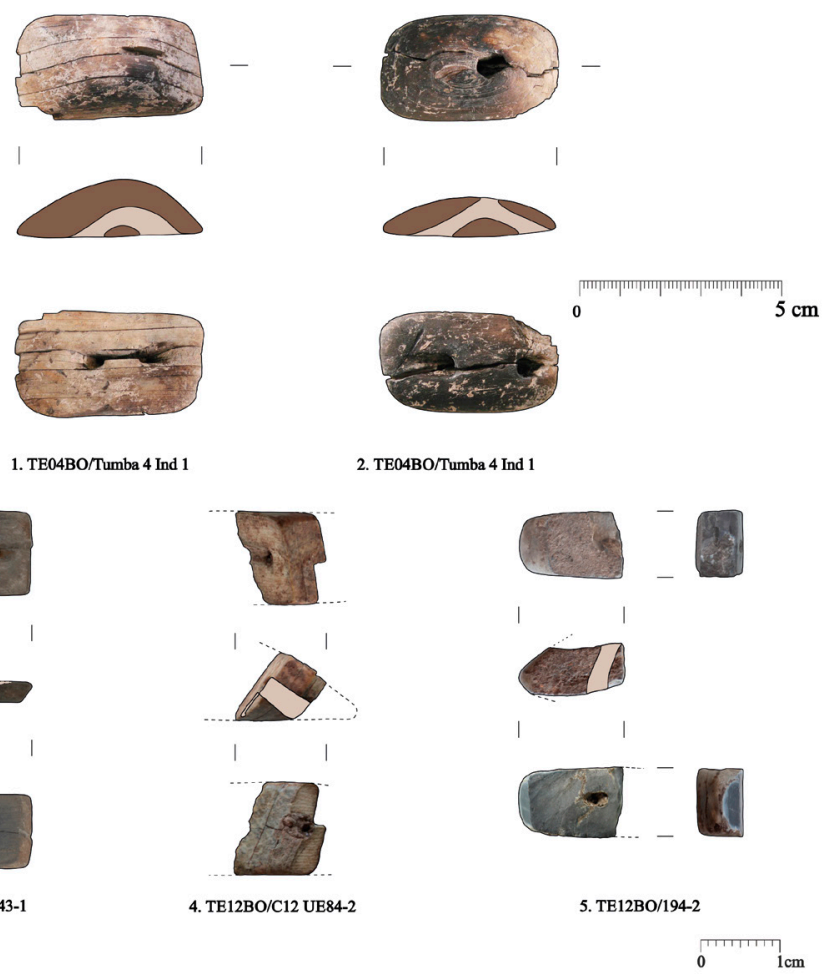

Figura 14. Botones

Figure 14. Buttons
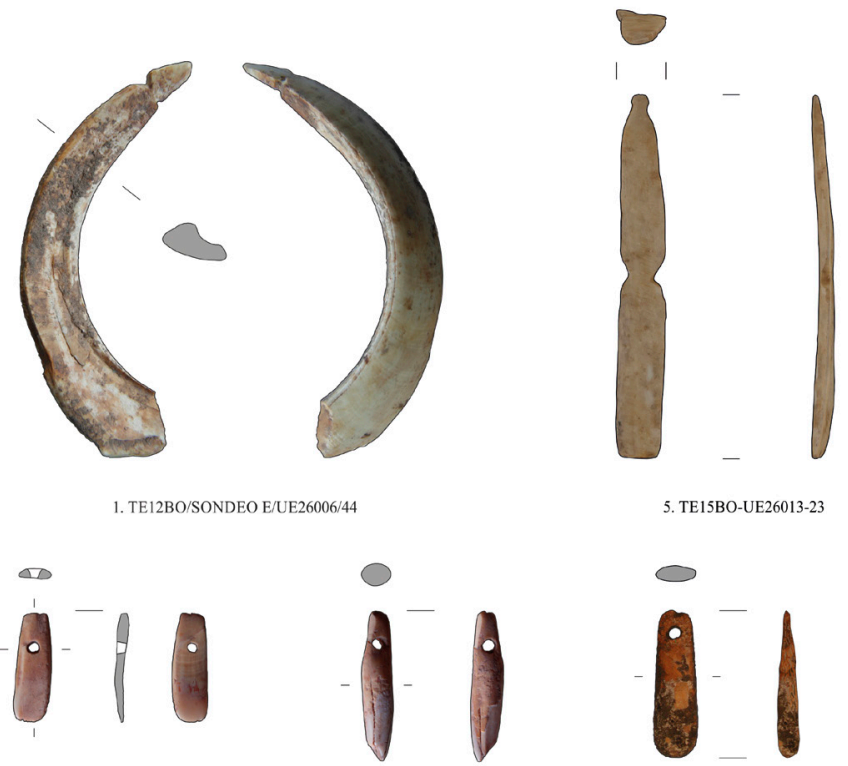

$\infty$

2. TE08BO/F13UE30

3. TE08BO/J7UE111

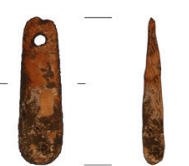

4. TE05/BO/D11/UE34

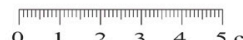

Figura 15. Adornos. Ídolo

Figure 15. Ornaments. Idol 
FAUNA E INDUSTRIA SOBRE MATERIA DURA DE ORIGEN ANIMAL DEL LUGAR SAGRADO...

\begin{tabular}{|c|c|c|c|c|}
\hline \multicolumn{5}{|c|}{ Elementos de materia dura de origen animal } \\
\hline Clasificación & Tipo & Subtipo & Materia prima & Sigla \\
\hline \multirow{21}{*}{ Útiles } & \multirow{19}{*}{ Apuntados } & \multirow{2}{*}{ Biapuntados } & Cérvido. Fragmento de asta & $\mathrm{TE} 12 \mathrm{BO} / 26003 / 1$ \\
\hline & & & No identificable & TE14BO/210.3 \\
\hline & & \multirow{3}{*}{ Hendidos } & Ovicaprino & TE13BO/197.3 \\
\hline & & & $\begin{array}{l}\text { Talla media. Frag. de hueso } \\
\text { plano }\end{array}$ & TE15BOUE 223.1 \\
\hline & & & $\begin{array}{l}\text { Talla media. Frag. diáfisis hueso } \\
\text { largo }\end{array}$ & TE15BO26l10UE2613.21 \\
\hline & & \multirow{5}{*}{$\begin{array}{l}\text { Hendido sobre base } \\
\text { articular }\end{array}$} & No identificable & TE13BO/184.1 \\
\hline & & & Talla media. Radio & TE14BO/210.7 \\
\hline & & & $\begin{array}{l}\text { Ovicaprino. Frag. medio-distal } \\
\text { de radio izquierdo }\end{array}$ & TE14BO/228.7 \\
\hline & & & $\begin{array}{l}\text { Talla media. Frag. prox. de } \\
\text { metápodo }\end{array}$ & TE15BOUE 234.1 \\
\hline & & & $\begin{array}{l}\text { Cervus elaphus. Frag. de cara } \\
\text { caudal de tibia izquierda }\end{array}$ & TE12BO/UE26007/6 \\
\hline & & \multirow{2}{*}{ Hendidos sin base } & $\begin{array}{l}\text { Ovicaprino. Frag. medio de } \\
\text { hueso largo }\end{array}$ & TE15BO26024.1 \\
\hline & & & $\begin{array}{l}\text { Talla media. Fragmento de } \\
\text { diáfisis de hueso largo }\end{array}$ & $\mathrm{TE} 14 \mathrm{BO} / 218.2$ \\
\hline & & Tubular sin base & $\begin{array}{l}\text { Lepus sp. Frag. medio de tibia } \\
\text { derecha }\end{array}$ & TE15BOUE 2613 Pz190 \\
\hline & & Facetado & Asta. Cérvido & TE12BO /26006/7 \\
\hline & & De economía & $\begin{array}{l}\text { Talla media. Fragmento de } \\
\text { diáfisis de hueso largo }\end{array}$ & TE14BO/210.9 \\
\hline & & \multirow{3}{*}{ Picos } & Cervus elaphus. Asta & TE15BO255-2 \\
\hline & & & Cérvido. Asta & $\mathrm{TE} 12 \mathrm{BO} / 26006 / 7$ \\
\hline & & & Ovicaprino. Cuerno & $\mathrm{TE} 14 \mathrm{BO} / 210.8$ \\
\hline & & $\begin{array}{l}\text { Punta de flecha. } \\
\text { Palmela? }\end{array}$ & $\begin{array}{l}\text { Talla media. Fragmento de } \\
\text { diáfisis de hueso largo }\end{array}$ & TE15BOUE 236.2 \\
\hline & \multirow[b]{2}{*}{ Espatulados } & $\begin{array}{l}\text { Alisador/Hendido de } \\
\text { base articular }\end{array}$ & $\begin{array}{l}\text { Bos taurus Frag. prox. de } \\
\text { diáfisis de metápodo }\end{array}$ & TE15BO26013.78 \\
\hline & & $\begin{array}{l}\text { Peine de alfarero o } \\
\text { Gradina Denticulado } \\
\text { Lateral }\end{array}$ & $\begin{array}{l}\text { Fragmento de diáfisis de hueso } \\
\text { largo }\end{array}$ & TE12BO/26018/P82 \\
\hline \multirow{18}{*}{ Adornos } & \multirow{8}{*}{ Cuentas } & \multirow{7}{*}{ Discoidales } & \multirow{7}{*}{ No identificable } & TE12BO/UE1/C7 \\
\hline & & & & $\mathrm{TE} 12 \mathrm{BO} / \mathrm{K} 5 / 1 / 1$ \\
\hline & & & & TE13BO/197.2 \\
\hline & & & & TE14BO/LIM.2 \\
\hline & & & & TE14BO/182.2 \\
\hline & & & & $\mathrm{TE} 12 \mathrm{BO} / 26010 / 2$ \\
\hline & & & & $\mathrm{TE} 12 \mathrm{BO} / \mathrm{BO} / \mathrm{UE} 1 / \mathrm{C} 7 / 2$ \\
\hline & & Perforada & Malacofauna (Collumbellidae) & $\mathrm{TE} 15 \mathrm{BO} / 26013$ \\
\hline & Cuenta/Botón & & No identificable & TE15BO/26010/2 \\
\hline & \multirow{5}{*}{$\begin{array}{l}\text { Botones con } \\
\text { perforación en } V\end{array}$} & \multirow{5}{*}{$\begin{array}{l}\text { Piramidales con base } \\
\text { rectangular }\end{array}$} & \multirow{5}{*}{ Marfil } & TE15BOUE 243-1 \\
\hline & & & & TE04BO Tumba4 Ind 1 \\
\hline & & & & TEO4BO Tumba4 Ind 1 \\
\hline & & & & TE12BOC122 UE84-2 \\
\hline & & & & TE12BO194-2 \\
\hline & \multirow{4}{*}{ Colgantes } & \multirow{4}{*}{ Perforados } & $\begin{array}{l}\text { Canino inferior de Sus scrofa. } \\
\text { macho }\end{array}$ & $\begin{array}{l}\text { TE12/BO/SONDEOE/ } \\
\text { ue26006/pz44 }\end{array}$ \\
\hline & & & Pieza dental ind. & TE08/BO/F13/UE30 \\
\hline & & & Incisivo de suido & TE08/BO/J7/UE111 \\
\hline & & & Hueso no identificable & TE08/BO/D11/UE34 \\
\hline $\begin{array}{l}\text { Ídolo/lámina con } \\
\text { escotaduras }\end{array}$ & & & Hueso no identificable & TE15BOUE26013/23 \\
\hline
\end{tabular}

Tabla 7. Tipologías de industria en materia dura de origen animal

Table 7. Types of industry in hard matter of animal origin 


\section{Datación}

Castillejo del Bonete estuvo en uso desde mediados del III milenio cal BC hasta mediados del II milenio cal BC. Se incluyen en este estudio dos nuevas dataciones.

Poz-736o6 procede de una vértebra de ovicaprino recuperada en la UE 208 (tabla 8, datación 5). Este estrato se caracteriza por su sedimento anaranjado suelto, que colmata y nivela los desniveles de la roca madre. Se utilizó para dotar de una disposición horizontal al suelo sobre el que se construyó el Túmulo I, que monumentaliza la cueva. En el interior de este estrato se han encontrado fragmentos de cerámicas elaboradas a mano y restos de fauna. El estrato fechado puede estar marcando el momento de monumentalización de la cueva.

La datación Poz-73665 (tabla 8, datación 6) procede de una falange humana recuperada en el nivel de uso (suelo) del Túmulo 2. Su estrato de procedencia es el piso de arcilla de io $\mathrm{cm}$ de espesor, con grandes losas de piedra caliza subyacentes. La roca madre caliza se encuentra debajo de esta capa. El espesor total del pavimento es de entre 25 y $30 \mathrm{~cm}$. En este lugar se han recuperado cerámicas, fauna, restos humanos, así como fragmentos de punzón de hueso, restos de un botón de marfil con perforación en forma de «V» y una cazoleta de aproximadamente $15 \mathrm{~cm}$ de diámetro excavada en piedra. Esta datación confirma el uso del Túmulo 2 a finales de la primera mitad del II milenio cal BC como lugar de enterramiento.

\section{Discusión}

E1 estudio de los restos de micromamíferos hallados en el Sondeo W de la Galería 2 de la cueva sepulcral de Castillejo del Bonete aporta información de especial interés desde varios puntos de vista. En primer lugar, la datación de una mandíbula de erizo (TEı2BO W UE26o2o; tabla 8, datación 8) permite precisar la antigüedad prehistórica tanto de la asociación de microvertebrados como de la utilización de la cueva como madriguera por un pequeño mamífero carnívoro. Atendiendo al conjunto de dataciones, la edad obtenida es la más reciente respecto al resto de materiales datados, a excepción

\begin{tabular}{|c|c|c|c|c|c|c|c|c|c|c|}
\hline & Contexto & Material & $\begin{array}{l}\text { Radiocarbon } \\
\text { lab code }\end{array}$ & $\begin{array}{c}\text { Edad }{ }^{14} \mathrm{C} \\
\mathrm{BP}\end{array}$ & $\begin{array}{c}\text { Cal BC } \\
(1 \sigma)\end{array}$ & $\begin{array}{c}\text { Cal BC } \\
(2 \sigma)\end{array}$ & $\% \mathrm{C}$ & $\% \mathbf{N}$ & $\begin{array}{c}\text { C:N } \\
\text { elemental }\end{array}$ & Referencia \\
\hline 1 & $\begin{array}{l}\text { Gran Túmulo } 1 . \\
\text { Tumba } 4 \text { (Ind. 2) }\end{array}$ & $\begin{array}{l}\text { Fémur } \\
\text { humano }\end{array}$ & Rome-1687 & $3720 \pm 70$ & $2271-1984$ & $\begin{array}{c}2340- \\
1921\end{array}$ & $*$ & $*$ & $*$ & $\begin{array}{l}\text { Benítez de } \\
\text { Lugo et alii, } \\
2014 \text { b: } 84 .\end{array}$ \\
\hline 2 & $\begin{array}{l}\text { Cueva. Galería } 2 . \\
\text { (TE12BO UE26o } \\
\text { 19) }\end{array}$ & $\begin{array}{l}\text { Falange } \\
\text { humana junto } \\
\text { a varsicitas }\end{array}$ & Beta-350768 & $3870 \pm 30$ & $2454-2293$ & $\begin{array}{c}2465- \\
2211\end{array}$ & * & * & * & $\begin{array}{l}\text { Benítez de } \\
\text { Lugo et alii, } \\
2014 \text { b: } 84 \text {. }\end{array}$ \\
\hline 3 & $\begin{array}{l}\text { Cueva. Galería } 2 . \\
\text { (TE12BO } \\
\text { UE26007) }\end{array}$ & Quercus ilex & Poz-67167 & $3385 \pm 35$ & $1736-1636$ & $\begin{array}{l}1769- \\
1565\end{array}$ & * & * & * & $\begin{array}{l}\text { Benítez de } \\
\text { Lugo et alii, } \\
2015 b: 114 \text {. }\end{array}$ \\
\hline 4 & $\begin{array}{l}\text { Cueva. Galería } 2 . \\
\text { (TE12BO } \\
\text { UE26015) }\end{array}$ & Rhamnus sp. & Poz-67168 & $3695 \pm 35$ & $2136-2034$ & $\begin{array}{l}2199- \\
1977\end{array}$ & $*$ & $*$ & * & $\begin{array}{l}\text { Benítez de } \\
\text { Lugo et alii, } \\
\text { 2015b: } 114 \text {. }\end{array}$ \\
\hline 5 & $\begin{array}{l}\text { Gran Túmulo } 1 . \\
\text { Base. } \\
\text { (TE13BO UE208) }\end{array}$ & $\begin{array}{l}\text { Vértebra } \\
\text { ovicáprino }\end{array}$ & Poz-736o6 & $4320 \pm 40$ & $3010-2892$ & $\begin{array}{l}3081- \\
2883\end{array}$ & 44,3 & 16,0 & 3,2 & $\begin{array}{l}\text { En este } \\
\text { trabajo }\end{array}$ \\
\hline 6 & $\begin{array}{l}\text { Túmulo 2. Suelo. } \\
\text { (TE13BO UE194) }\end{array}$ & $\begin{array}{l}\text { Falange } \\
\text { humana }\end{array}$ & Poz-73665 & $3610 \pm 35$ & 2022-1926 & $\begin{array}{l}2120- \\
1885\end{array}$ & 42,9 & 15,7 & 3,2 & $\begin{array}{l}\text { En este } \\
\text { trabajo }\end{array}$ \\
\hline 7 & $\begin{array}{l}\text { Gran Túmulo } 1 . \\
\text { Tumba } 1 \\
\text { TE03BO D8 } \\
\text { UE12 }\end{array}$ & $\begin{array}{l}\text { Pieza dental } \\
\text { humana }\end{array}$ & PSUAMS-2077 & $3565 \pm 25$ & * & $\begin{array}{c}2014- \\
1781\end{array}$ & 44,5 & 16,6 & * & $\begin{array}{l}\text { Olalde et } \\
\text { alii, } 2019\end{array}$ \\
\hline 8 & $\begin{array}{l}\text { Cueva. Galería } 2 \\
\text { (Sondeo W). } \\
\text { TE12BO W } \\
\text { UE26020 }\end{array}$ & $\begin{array}{l}\text { Mandíbula } \\
\text { Erinaceus } \\
\text { europaeus }\end{array}$ & UCIAMS-205912 & $3430 \pm 20$ & * & $\begin{array}{l}1869- \\
1665\end{array}$ & 42,4 & 15,3 & 3,2 & $\begin{array}{l}\text { Domínguez } \\
\text { García et } \\
\text { alii, } 2019\end{array}$ \\
\hline
\end{tabular}

Tabla 8. Castillejo del Bonete. Dataciones

Table 8. Castillejo del Bonete. Dating 
de la de un fragmento de carbón de Quercus ilex (TE12 $\mathrm{BO} \mathrm{UE}_{2} 6007$ ). Los intervalos cronológicos calibrados de ambas dataciones se solapan ampliamente. Esos restos de carbón fueron encontrados también en el interior de la Galería 2 de la cueva, en el contexto de un resto de combustión depositado al pie de una pintura antropomorfa esquemática; es posible que se trate de una evidencia de la iluminación relacionada con esta pintura. El elevado número de restos de microvertebrados identificados, cuyo origen se asocia a la actividad depredadora de un mamífero carnívoro, indica que la cueva fue utilizada como letrina durante un periodo de tiempo continuado. Este hecho sugiere que, durante la formación de la asociación, la cueva sepulcral del Gran Túmulo I de Castillejo del Bonete tendría comunicación con el exterior pero no estaría frecuentada por grupos humanos, ya que una actividad antrópica recurrente habría impedido el uso de la cueva por parte del carnívoro que acumuló los restos. A esta idea se suma el hecho de que los restos óseos de un depredador de esta clase fueron encontrados en primer lugar al entrar a la cueva y al realizar las excavaciones arqueológicas. Estos restos habrían sido removidos si la cueva hubiera sido transitada por humanos tras morir el carnívoro. Por tanto, es posible afirmar que la fecha obtenida para la asociación de micromamíferos (1869-I665 cal. BC) podría corresponder a un momento en el que un pequeño carnívoro aún podía acceder a la cueva, que ya estaba en desuso como sepulcro monumental. En segundo lugar, el conjunto de especies de microvertebrados sirve como herramienta de reconstrucción de las condiciones climáticas y de los paisajes que existieron cuando se formó el yacimiento. En este sentido, en general, los paisajes y el clima dominantes en el momento de generarse esta muestra no debieron ser muy diferentes de los actuales, ya que la mayoría de las especies identificadas se encuentran hoy en el sureste de la provincia de Ciudad Real o en su entorno inmediato. Trabajos en curso permitirán concretar las condiciones ambientales desde un punto de vista cuantitativo a partir de distintos proxies (herpetofauna, micromamíferos) y mediante el uso de distintas disciplinas científicas.
Por último, la asociación de micromamíferos de Castillejo del Bonete documenta el proceso de formación de las asociaciones de mamíferos actuales en la Península. Así, junto a una mayoría de especies presentes en el territorio ibérico desde el Pleistoceno, encontramos una (Mus spretus) (figura I6), que constituye una introducción reciente en las faunas ibéricas procedente del norte de África, pudiendo considerarse resultado y evidencia indirecta navegación prehistórica (Dobson, 1998; Stoetzel, 2013; Lalis et alii, 2019). Los restos son abundantes (es la tercera especie más abundante en el yacimiento). Ello indica que en este momento su población estaba ya bien asentada en el sur de la Península. Además, la ausencia en Castillejo del Bonete de otras especies como Mus musculus, Suncus etruscus, Rattus rattus o Rattus norvegicus - que en la actualidad habitan en el entorno del yacimiento- señala que la incorporación de estas especies a la fauna ibérica se produjo en un momento posterior al de la formación de este registro, habida cuenta de que el elevado tamaño muestral de los restos de micromamíferos permite interpretar en este sentido la ausencia de estas especies en la asociación. Este aspecto ha sido tratado con mayor profundidad por Domínguez García et alii (20rga) mediante una amplia revisión del registro de estas especies en el sudoeste de Europa, destacando la relevancia de la asociación documentada en Castillejo del Bonete. Por tanto, en consonancia con trabajos previos (Morales Muñiz et alii, 1995; Audoin-Rouzeau y Vigne, 1994; Cucchi et alii, 2005; Lalis et alii, 2019), esta asociación de micromamíferos pone de manifiesto que la introducción y colonización de Mus spretus tuvo lugar a partir el Neolítico final, mientras que Mus musculus, Suncus etruscus y Rattus spp colonizaron el sudoeste europeo en periodos posteriores a la edad obtenida para la asociación de microvertebrados de Castillejo del Bonete.

$\mathrm{El}$ análisis de los restos arqueológicos de fauna doméstica procedentes de Castillejo del Bonete proporciona resultados similares a los documentados en otros yacimientos del Bronce de La Mancha, como son las motillas del Azuer (en donde se han detectado además coprolitos de ovicápridos y suidos) y Los Palacios (Driesch y Boessneck, 1980), Los Romeros (García Pérez, 1987) o El Retamar (Colmenarejo et alii, 1987; Lenguazco, 20I2). 


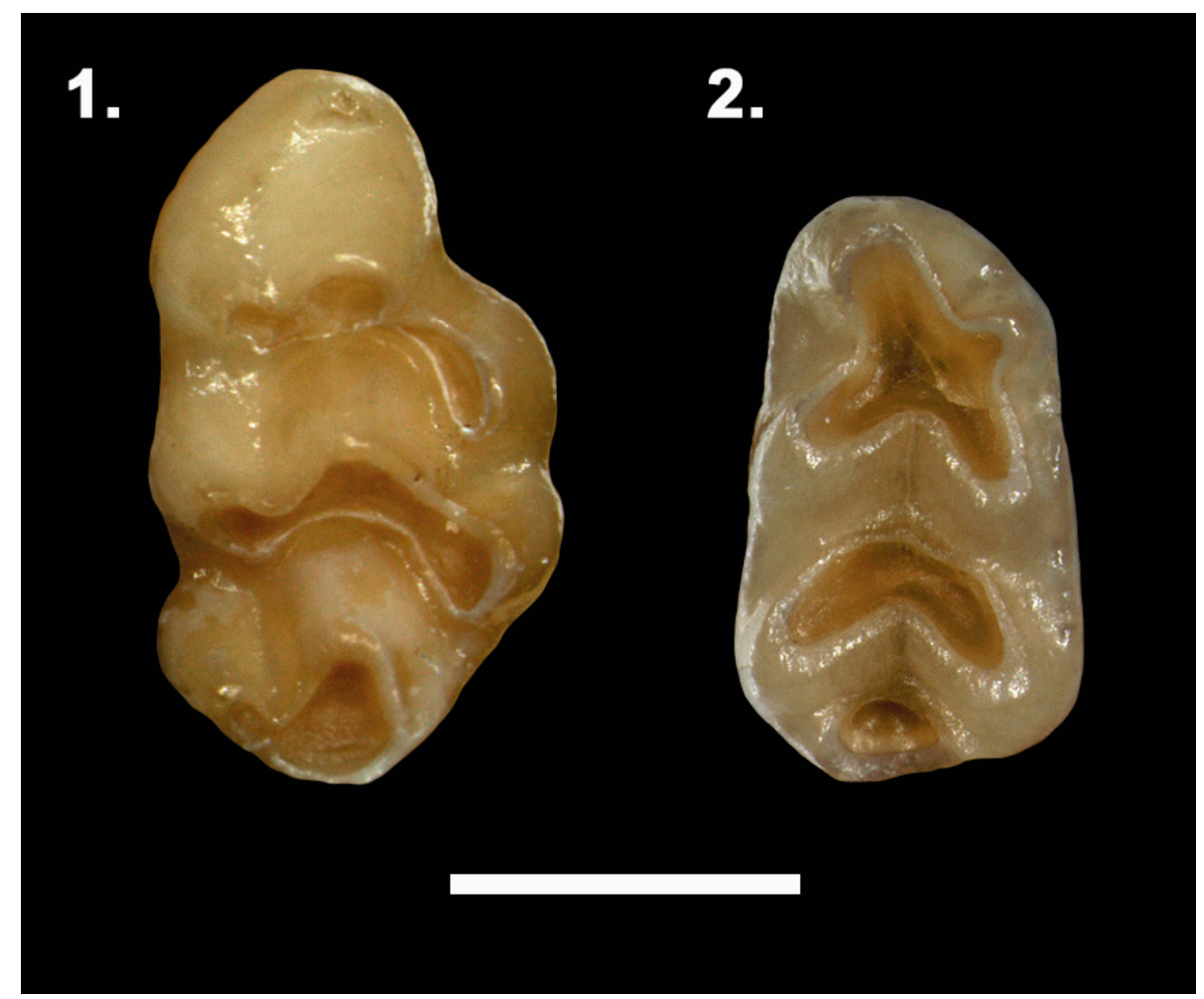

Figura 16. Elementos de Mus spretus de la asociación de micromamíferos documentada en Castillejo del Bonete: 1. Primer molar superior (M1) derecho; 2. Primer molar inferior derecho (m1). Barra de escala: $1 \mathrm{~mm}$. Modificada de Domínguez García et alii (2019)

Figure 16. Mus spretus elements from the association of small mammals documented in Castillejo del Bonete: 1. Right upper first molar (M1); 2. Lower right first molar (m1). Scale bar: 1 mm. Modified from Domínguez García et al. (2019)

En Castillejo del Bonete, los patrones de edad de sacrificio de las cabañas de ovicaprinos y bovinos reflejan un sistema de explotación mixta para las dos especies, en el cual la mayoría de los individuos habrían sido mantenidos con vida hasta su edad adulta para poder aprovechar los recursos en vida del animal, además de los cárnicos: la leche y la lana en el caso de los ovicaprinos, y la leche y la fuerza de trabajo en el caso de los bovinos. Resulta innegable la utilización de esta última especie como fuerza de trabajo, ya sea en funciones de tiro, carga o transporte. Estos usos la convierten en especie muy valorada en economías prehistóricas, sobre todo en aquellas en las cuales la envergadura de la explotación agrícola puede depender de este animal. Este hecho condiciona la gestión de los rebaños, permitiendo a algunos de estos individuos sobrevivir a una muerte temprana, con el fin de ser destinados a labores de reproducción y explotación de los productos secundarios, entre los cuales se encontrarían los relacionados con la fuerza física. Cabe recordar que en el yacimiento se han documentado varios fragmentos de queseras (Benítez de Lugo et alii, 20I4-2015: 208, fig. 29; Fernández-Martín et alii. 20I5: I4I, fig. 6.43). El grupo de los suidos presenta también un patrón de algunos animales sacrificados jóvenes en su óptimo cárnico, $\mathrm{y}$ varios representantes adultos para asegurar la reproducción de la especie.

Rituales de comensalidad debieron formar parte del programa de actividades realizadas en este lugar sagrado, dejando como evidencias restos de fauna consumida (Orri, 2004), vajilla varia y algunas hogueras, siempre relacionadas con espacios funerarios (en el interior de la cueva sepulcral, encima de la Tumba 4, etc.). Estos restos se han encontrado dispersos por el yacimiento o formando parte de depósitos colocados en estructuras siliformes o meros hoyos abiertos y vueltos a cerrar en el cuerpo del túmulo. Estas estructuras ya han sido descritos en trabajos anteriores (Benítez de Lugo et alii, 20I4a).

El taxón más representado es el de las ovejas. En este punto es importante señalar que Castillejo 
del Bonete domina un corredor natural estratégico que comunica Levante con Andalucía y la Meseta, que ha fosilizado en la Cañada Real de Andalucía; una ruta ganadera de primer orden desde el punto de vista de la explotación ganadera extensiva. Controlando también rutas ganaderas se encuentran otros yacimientos del Bronce de La Mancha, como es el caso de la motilla de E1 Retamar (Argamasilla de Alba). La localización de yacimientos relevantes del Calcolítico y Cultura de las Motillas vinculados a vías ganaderas tradicionales, así como la presencia abundante de ovicaprinos en estos mismos yacimientos, son argumentos que permiten defender la existencia de movimientos ganaderos ya desde la Prehistoria en La Mancha. Las motillas, que fueron puntos de aguada en un entorno caracterizado por la aridez debido al Evento Climático $4.2 \mathrm{ka} \mathrm{cal} \mathrm{BP,}$ debieron desempeñar un papel trascendental para la supervivencia y desarrollo de un modelo económico que en La Mancha fue fundamentalmente ganadero (Benítez de Lugo y Mejías, 20r6b). Todavía hoy la oveja manchega es fuente generadora de riqueza en la región, siendo su leche una de las más valoradas y costosas, y viéndose exportados sus productos a todo el mundo (Agroclm, 20I6; Oviespaña, 20I9).

Se han encontrado nueve restos de cuatro individuos Canis familiaris. Aparecen dispersos junto a otros restos de alimentación, pero en el caso de los perros no presentan trazas de carnicería ni están termoalterados (Orri, 2004). Los canes son fundamentales para controlar los rebaños y protegerlos de depredadores. En vida pueden considerarse vinculados con el cuidado de la cabaña ovina, pero la frecuencia de cráneos de estos animales en depósitos rituales calcolíticos obliga a considerar la posibilidad de que la presencia de restos de perros en Castillejo del Bonete fuese resultado de un gesto simbólico deliberado; quizás de un rito de sacrificio para ser enterrados junto a sus dueños (Delibes et alii, 20I9; Daza, 20II).

Cabe resaltar la ausencia de équidos en la muestra de fauna analizada en este yacimiento. En el estado actual de los conocimientos cabe deducir que los caballos no eran consumidos ni enterrados en lugares como Castillejo del Bonete. Sin embargo, hay que recordar que sí está atestiguada la presencia realmente abundante de caballos en lugares de aguada como fue la motilla del Azuer, en un momento en que La Mancha sufría un fuerte período de sequía; allí se encuentran restos como cráneos, mandíbulas o huesos largos (Aranda et alii, 2008: 253).

Respecto a los conejos es significativo que la mayoría de individuos aportan una representación anatómica bastante elevada y una nula fragmentación de los huesos. La existencia de esta especie en yacimientos arqueológicos es bastante común, pero en pocas ocasiones ha sido posible diferenciar entre un depósito intencionado y lo que puede ser una fauna intrusiva, debido a que estos animales, por sus hábitos fosores, suelen utilizar esta clase de espacios funerarios como madrigueras (Blasco et alii, 20I4: 22; Liesau y Schubart, 2006; Liesau, 2012). En este caso se identifican como bioturbaciones e intrusiones naturales de fauna local, sin que se haya detectado hasta el momento ninguna evidencia de un individuo consumido.

La presencia de aves podría haber sido más importante de lo que reflejan sus restos recuperados (no identificados por el momento), ya que los huesos de este taxón, debido a su tamaño y fragilidad, pueden quedar prácticamente eliminados durante el proceso de consumo.

En cuanto al inventario de la industria realizada en materia dura de origen animal podemos señalar, en primer lugar, la existencia de diferentes tipologías de los punzones recuperados en Castillejo de Bonete presentando, además, una amplia vigencia cronológica, al igual que su distribución geográfica ya que aparecen en todo el ámbito intra/extra peninsular

La punta de tipo "Palmela» presente en el yacimiento cuenta con una distribución que abarca toda la geografía peninsular llegando, incluso, a Francia, si bien muestran concentraciones en la Submeseta Norte, Valencia y el suroeste peninsular. En la Submeseta Norte las puntas aparecen en yacimientos funerarios y de habitación; en estos últimos de manera menos frecuente (Delibes et alii, 1999; Garrido-Pena, 2000 Altamirano, 2009; Altamirano et alii, 2013). También se encuentran en otras regiones, en particular en la Comunidad Valenciana, en Cataluña y en Andalucía. Así, por ejemplo, encontramos varios ejemplares en yacimientos como Cuenca de Vera (Almería) 
(Maicas-Ramos, 2007), Cerro de la Virgen (Granada) (Molina González et alii, 20I4), las motillas del Azuery El Retamar (Ciudad Real) (Altamiro, 2009; Altamiro et alii, 2013), La Magdalena y los Humanejos (Madrid) (Blasco et alii, 2014) o el Portalón de Cueva Mayor (Burgos) (Pérez-Romero et alii, 2015).

Los colgantes rectangulares o subrectangulares realizados en hueso presentan una amplia distribución en Europa. En España encontramos ejemplares confeccionados en piedra, hueso o en concha en el País Valenciano, Murcia y en el valle del Ebro (Pascual, 1996). Aunque las referencias son escasas, se han referido hallazgos de colgantes de forma subrectangular también en Andalucía en la Cueva de la Carigüela (Píñar) (Pellicer, I964). Los realizados sobre concha aparecen en todos los horizontes cronológicos y su distribución geográfica es muy amplia, mayor cuanto más próximos a las zonas costeras ya que constituyen, además una fuente de alimentación. La presencia de este tipo de conchas en regiones interiores peninsulares habla de contactos a larga distancia con otros grupos (García Barbo et alii, 20I4).

Los colgantes sobre dientes de animales han sido documentados en prácticamente todas las culturas prehistóricas. Los realizados sobre colmillo de jabalí han sido recuperados en algunos yacimientos andaluces de Granada y Málaga, destacando el conjunto de la Cueva de los Murciélagos. Estos son más frecuentes en los ajuares funerarios de la cultura neolítica catalana. En el sur de Francia también son muy abundantes, presentando una cronología que va desde el Neolítico a la Edad del Bronce (Álvarez-Fernández, 2006).

Contamos también con la presencia de botones realizados en marfil, materia prima que tiene un origen muy lejano, ya que su fuente de aprovisionamiento es extracontinental. Tras los análisis efectuados en los contextos arqueológicos se ha podido determinar que el marfil llega a esta zona desde tierras del norte de África, a través de yacimientos costeros como los de San Antón (Alicante) o los de Fuente Álamo, El Oficio o El Argar (Almería) (Schuhmacher et alii, 20I3; Benítez de Lugo et alii, 20I5a). La presencia de esta clase de piezas en yacimientos calcolíticos y del Bronce peninsular se debería a un comercio realizado en función de la demanda de objetos de prestigio, por parte de algunos de los grupos de más elevado estatus socioeconómico; comercio que explicaría la presencia en algunos yacimientos magrebíes de cerámica campaniforme, puntas de Palmela y puñales de lengüeta (Harrison y Gilman, 1977), o de productos metálicos con morfometrías y asignaciones isotópicas similares a los del valle del Guadalquivir (Nocete, 200r: 96). Para concluir señalaremos que la presencia de estos objetos realizados con marfil, estarían dotados de un simbolismo especial, pues a sus propias características físicas se uniría su escasez, su procedencia lejana y, probablemente, las referencias que podían circular sobre el tipo de animal del que procedía el marfil.

En síntesis, en este centro ceremonial de la Prehistoria se encuentran objetos de uso cotidiano, entre los que están fauna consumida (Orri, 2004) y útiles o adornos personales elaborados sobre materia dura animal. Estos materiales se hallan en asociación a restos humanos dentro de la cueva sepulcral o empotrados en el cuerpo de los túmulos y sus alrededores; ya sea dentro de recintos, depósitos o estructuras siliformes. Las dataciones muestran la monumentalización de este lugar a partir de 308I cal. BC, estando ya probablemente su cueva sepulcral en desuso en $1665 \mathrm{cal}$. BC.

Castillejo del Bonete no es una motilla ni una morra (está en la ladera de la Meseta, no sobre un acuífero o encima de un montículo; su emplazamiento deriva de la cueva a la que monumentaliza, situada sobre un corredor natural que comunica Andalucía con Levante y Castilla). Las motillas probablemente utilizaron el código simbólico que está fosilizado en Castillejo del Bonete. Este estudio permite avanzar, por tanto, en aspectos sociales y simbólicos de la Cultura de las Motillas, en un momento de gran estrés ambiental causado por la sequía derivada del Evento Climático $4.2 \mathrm{ka}$ BP (Lillios et alii, 20r6). En ese momento una sociedad resiliente supo reorganizarse al sur de la Meseta en torno a las motillas para sobrevivir, desarrollando una economía fundamentalmente ganadera que utilizó y monumentalizó el territorio; especialmente los corredores naturales de paso, por los cuales circularon personas e ideas, además de muchas ovejas y cabras desde tiempos neolíticos (Benítez de Lugo et alii, 20I9). 


\section{Conclusión}

Castillejo del Bonete ha proporcionado una asociación de microvertebrados excepcional, constituyendo el registro más abundante y diverso documentado hasta la fecha en yacimientos de la Edad del Bronce del sur de la península ibérica. Sus características y antigüedad indican que el conjunto de restos de microvertebrados fue acumulado por un mamífero carnívoro al final de la fase de uso de la cueva como cámara mortuoria por parte de los grupos humanos que frecuentaron este lugar sagrado. Además, el buen registro de Mus spretus documentado en la asociación demuestra que esta especie se encontraba bien representada en el sur de la península ibérica en la Edad del Bronce, mientras que otras especies ausentes en la muestra (Mus musculus, Suncus etruscus, Rattus rattus y Rattus norvegicus) no habían colonizado el sudoeste de Europa en este período (figura I6).

La estrategia de subsistencia de las personas que utilizaron Castillejo de Bonete estaba basada en la ganadería, con el consumo, principalmente, de la tríada doméstica: ovicaprinos, bovinos y cerdos. Los perfiles de mortalidad de estos tres taxones indican un aprovechamiento mixto, de consumo de productos primarios y secundarios. Sin embargo, los altos porcentajes de animales adultos sugieren un consumo enfocado a los productos secundarios (leche y productos lácteos) y el mantenimiento de las cabañas para la reproducción y la cría, especialmente la ovina. En los casos de los bovinos la edad adulta de sacrificio indica un uso de los animales para carga y tracción.

La muestra de industria ósea está compuesta por un variado conjunto tipológico que va desde piezas muy poco elaboradas hasta las que presentan un complejo trabajo y siguen esquemas tecnotipológicos muy ajustados y reconocidos en una amplia geografía. Se trata de piezas que pueden ser consideradas de uso cotidiano, pero que han adquirido una segunda funcionalidad al ser depositadas en este lugar al servicio de un programa ritual funerario. Buena parte de los artefactos apuntados presentan una mínima transformación del soporte natural, conservando parte de sus rasgos anatómicos distintivos epífisis, diáfisis, canal medular, etc.). Los objetos de adorno, sin embargo, presentan un acabado formal cuidado, modificando de forma notable la morfología original del soporte para obtener la forma deseada y el pulido de las superficies.

La existencia de un conjunto de botones realizados en marfil formando parte de un importante ajuar dentro de un contexto funerario (piezas de metal y de variscita, indicios de comensalidad, etc.), estarían relacionados con las manifestaciones de ostentación y prestigio al alcance de pocos individuos, lo que testimoniaría una sociedad jerarquizada.

\section{Agradecimientos}

La Junta de Comunidades de Castilla-La Mancha, el Ayuntamiento de Terrinches y la empresa $\mathrm{E}_{2} \mathrm{IN}_{2}$ financian la investigación en Castillejo del Bonete. Honorio Javier Álvarez García (arqueólogo), María Benito Sánchez, Alexandra Muñoz García e Isabel Beltrán Gil (antropólogas) han codirigido en diferentes momentos las investigaciones en Castillejo del Bonete. Este trabajo se enmarca dentro del proyecto I+D REDISCO (HAR2017-88035-P).M.A.G.P.pertenece al grupo de

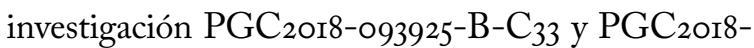
094125-B-Ioo (MCIU/AEI/FEDER, UE).M.A.G.P. actualmente trabaja en el Museo Arqueológico Regional/Fundación General de la Universidad de Alcalá de Henares, con un contrato PTA2or8-OI5I45-I del Ministerio de Ciencia y Innovación. ÁCDG es beneficiario de las Ayudas Predoctorales de la Universidad

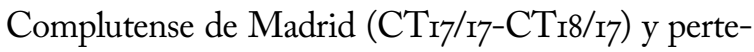
nece al Grupo de Investigación UCM 970827 Ecosistemas Cuaternarios

Los revisores de este trabajo han contribuido a su mejora. 
Bibliografía

Alday, A., Juez, L., Pérez Romero, A., Adán, G.E., Santos, E., Galindo-Pellicena, M.A., Carretero, J.M. y Arsuaga, J.L. (20II): "La industria ósea de El Portalón de Cueva Mayor (Sierra de Atapuerca, Burgos): Biapuntados, puntas de flecha y agujas, morfología y funcionalidad”. Munibe Antropologia-Arkeologia, 62: 27-249.

Altamirano, M. (2009): "La industria de hueso de un yacimiento arqueológico de la Edad del Bronce: la motilla de El Azuer (Daimiel, Ciudad Real)". Arqueología y Territorio, 6: 39-55.

Altamirano, M. (20II): "Worked bone industry from the Bronze Age of Central Iberia. The settlement of La Motilla del Azuer. Written in bones: between technology and social relations". En J. Baron, B. Kufel-Diakowska (eds.): Procedings of the $7^{\text {th }}$ Meeting of the ICAZ Worked Bone Research Group at Wroctaw, 7-II September 2009. Uniwersytet Wrocławski. Wrocław: 273-284.

Altamirano,M.,Nájera Colino, T.y Molina González, F. (2013): "Bronze Age Osseous Projectile Points from the Archaeological Site of La motilla de E1 Azuer". The Sound of Bones: Proceedings of the $8^{\text {th }}$ Meeting of the ICAZ Worked Bone Research Group in Salzburg 20Ir: 9-24. Schriften zur Archäologie und Archäometrie der Paris Lodron-Universität Salzburg. Band 5: 9-24.

Álvarez Fernandez, E. (2006). Los objetos de adorno-colgantes del Paleolitico superiory del Mesolítico en la Cornisa Cantábrica y en el Valle del Ebro: una visión europea. Colección Vítor, ${ }^{\circ}$ 195. Ed. Universidad de Salamanca. Salamanca.

Agroclm (2016): "La leche de las ovejas manchegas: la más cara del mundo". Diario del Campo de Castilla-La Mancha 12/12/2016. Consulta: 26/9/2020. https://www.agroclm.com/2016/r2/12/la-leche-lasovejas-manchegas-la-mas-cara-del-mundo/.

Aranda, G., Fernández, S., Haro, M., Molina, F., Nájera, T.y Sánchez-Romero, M. (2008): "Water control and cereal management on the Broze Age Iberian Peninsula: la motilla del Azuer". Oxford Journal of Archaeology, 27 (3): 24I-259.

Audoin-Rouzeau, F. y Vigne, J.D. (1994): "La colonisation de l'Europe par le rat noir (Rattus rattus)". Revue de Paléobiologie, I3(I): I25-I45.
Averbouh, A. y Provenzano, N. (1998-1999): "Propositions pour une terminologie du travail préhistorique des matières osseuses: I - les techniques". Prébistoire Anthropologie Méditerranéennes, 7-8: 5-25.

Balsera, V., Bernabeu Aubán, J., Costa-Caramé, M., Díaz-Del-Río, P., García Sanjuán, L. y Pardo, S. (2015): "The radiocarbon chronology of southern Spain's late Prehistory (5600-Iooo CAL BC): a comparative review". Oxford Journal of Archaeology, 34 (2): 139-156. https://doi.org/ro.IIII/ojoa.I2O53

Barea-Azcón,J.M., Ballesteros-Duperón, E., Gil-Sánchez, J.M. y Virgós, E. (2010): "Badger Meles meles feeding ecology in dry Mediterranean environments of the southwest edge of its distribution range". Acta Theriologica, 55 (I): 45-52.

Barone, R. (1999): Anatomie Comparée des Mammiferes Domestiques. Tome I et II. Vigot Frèges. Paris.

Benítez de Lugo Enrich, L., Álvarez,H.J., Moraleda, J. y Molina,M. (2007): "Consideraciones acerca del Bronce de La Mancha a partir de la investigación de la cueva prehistórica fortificada de Castillejo del Bonete (Terrinches, Ciudad Real). Campañas 2003-2005”. En J.M. Millán y C. Rodríguez Ruza (coords.): Actas de las I Jornadas de Arqueología de Castilla-La Mancha (Cuenca, 2005). Universidad de Castilla-La Mancha. Cuenca: 23I-262.

Benítez de Lugo Enrich, L. (2010): Las motillas y el Bronce de La Mancha. Anthropos. Valdepeñas.

Benítez de Lugo Enrich, L. (20II): "Las motillas del Bronce de La Mancha: treinta años de investigación arqueológica”. Bibliotheca Praehistorica Hispana XXVIII: I4I-I62.

Benítez de Lugo Enrich, L., Álvarez, H.J., Fernández, S., Mata, E., Moraleda,J., Morgado, A., Palomares, N., Odriozola, C., Morgado, A. y Salazar-García, D.C. (20I4a): "Castillejo del Bonete (Terrinches, Ciudad Real): complejo tumular prehistórico de la Cultura de las Motillas en el Alto Guadalquivir". Menga, Revista de Prehistoria de Andalucía, 5: 15I-I74.

Benítez de Lugo Enrich, L., Mejías, M., López, J., Álvarez,H.J.,Palomares, N., Mata, E. Moraleda, J., Menchén, G., Fernández, S. Salazar-García, D.C., Odriozola, C., Benito, M. y López, J.A. (20I4b): "Aportaciones hidrogeológicas al estudio arqueológico de los orígenes del Bronce de La Mancha: la cueva monumentalizada de Castillejo del Bonete (Terrinches, Ciudad Real-España)". Trabajos de Prehistoria, 7I (I): 76-94. https://doi.org/Io.3989/ tp.20I4.I2I25. 
Benítez de Lugo Enrich, L., Álvarez, H.J., Palomares, N., Mata, E. y Moraleda, J. (2014-2015): "Investigación y gestión de un complejo monumental prehistórico en el borde meridional de la Meseta: Castillejo del Bonete (Terrinches, Ciudad Real). Quince años de intervenciones arqueológicas (2003-2015)". Arse, 48-49: 173-218.

Benítez de Lugo Enrich, L. y Mejías, M. (2015): "La prehistórica Cultura de las Motillas: nuevas propuestas para un antiguo problema". Veleia, 32: III-I24. doi: I0.I387/veleia.I498I

Benítez de Lugo Enrich, L., Schuhmacher, T.X., Palomares, N., Álvarez, H.J., Mata Trujillo, E., Moraleda, J., Menchén, G. y Salazar-García, D.C. (20I5a): "Marfil para los muertos en la Cultura de las Motillas: los botones de Castillejo del Bonete (Terrinches, Ciudad Real)". Madrider Mitteilungen, 56: 40-6r.

Benítez de Lugo Enrich, L., Palomares, N., Álvarez, H.J., Barroso Bermejo, R., Benito, M., Hugues Blain, H., Bueno Ramírez, P., De Balbín, Fernández Martín, S., López, J.A., Galindo, M.A., Garrido, M.A., Laplana, C., Mata, E., Menchén, G., Montero, I., Moraleda S, J., Morgado, A., Odriozola, C., Polo, E., Ruiz, M., Sevilla, P., Schuhmacher,T.X.y Salazar-García, D.C. (2015b): "Paleoecología y cultura material en el complejo tumular prehistórico de Castillejo del Bonete (Terrinches, Ciudad Real)". Menga, Revista de Prehistoria de Andalucía, 6: II2-I40.

Benítez de Lugo Enrich, L. y Mejías, M. (20I6a): "Aspectos hidrogeológicos, paleoambientales, astronómicos y simbólicos del Bronce de La Mancha". Arpi, 4: 345-356.

Benítez de Lugo Enrich, L. y Mejías, M. (20I6b): "Hidrogeología y captación de aguas subterráneas en La Mancha durante la Prehistoria Reciente: la gestión de los recursos hídricos en la Cultura de las Motillas". Archivo de Prehistoria Levantina 31: I37-I68.

Benítez de Lugo Enrich, L. y Mejías, M. (2017): “The hydrogeological and paleoclimatic factors in Bronze Age Motillas Culture of La Mancha: the first hydraulic culture in Europe". Hydrogeology Journal 25 (7): 1931-1950. doi: 10.1007/sio040-0I7-1607-Z
Benítez de Lugo Enrich, L. (2018a): "Rituales funerarios neolíticos, calcolíticos y de la Edad del Bronce en la provincia de Ciudad Real: Cerro Ortega (Villanueva de la Fuente) y Castillejo del Bonete (Terrinches)". Anejos de Cuadernos de Prehistoria y Arqueología de la Universidad Autónoma de Madrid, 3: 153-168. http:// dx.doi.org/ro.I5366/ane3.rubiozor8.oII

Benítez de Lugo Enrich, L. (2018b): "Arqueología Prehistórica en Castilla-La Mancha”. La Albolafia, 15: 10-34.

Benítez de Lugo Enrich, L. y Esteban, C. (2018): "Arquitecturas simbólicas orientadas astronómicamente durante el Calcolítico y la Edad del Bronce en el sur de la Meseta”. Spal, 27 (I): 6I-87. http://dx.doi.org/Io.I2795/spal.20I8i27.03

Benítez de Lugo Enrich, L., Alañón Flox, A., Barrio Aldea, C., Francés Negro, M., Márquez Mora, B., Menchén Herreros, G., Moraleda Sierra, J., Rojas Rodríguez Malo,J.M.y Salazar-García,D.C.(20I9): "Cerro Ortega (Villanueva de la Fuente, Ciudad Real): un abrigo sepulcral con inhumación múltiple durante la transición Neolítico-Calcolítico al sur de la Meseta”. Marq. Arqueología y museos, Io: II-24. Benítez de Lugo Enrich, L., Baeza Chico, E., Delvene, G., Gutiérrez Sáez, C., Márquez Mora, B., Menchén Herreros, G., Muñoz Moro, P. y Odriozola Lloret, C. (2020a): "Nuevos análisis traceológicos, arqueométricos y petrológicos de material metálico y lítico recuperado en un lugar sagrado de la Cultura de las Motillas: Castillejo del Bonete (Terrinches, Ciudad Real)". Anejos de Cuadernos de Prebistoria y Arqueología de la Universidad Autónoma de Madrid 4: 7I-8I. http:// dx.doi.org/10.15366/ane4.ochoa2020.003

Benítez de Lugo Enrich, L. y Mejías Moreno, M. (2020b): "Climatic crisis, socio-cultural dynamics and landscape monumentalization during the Bronze Age of La Mancha: the Motillas Culture as adaptation to the changes of the end of the $3^{\text {rd }}$ mill. $\mathrm{BC}$ ". Landscapes as resources assemblages in the Bronze Age of Southern Spain (Linares, 26-27 septiembre 20Ig). Universität Tübingen.

Benítez de Lugo, L., Mejías, M., López Saéz, J.A. y Esteban, C. (2020c): The origins of social inequality in prehistoric Europe: rituals and monuments to control wealth in Bronze Age of La Mancha. Bibliotheca Praehistorica Hispana, XXXVI. CSIC. Madrid. ISBN: 978-84-00-09264-I. 
Blanco González, A. y Esparza Arroyo, A. (2019): "Conectividad en la Edad del Bronce del occidente de la península ibérica. Examinando la relación entre sitios y vías pecuarias mediante SIG*”. Trabajos de Prehistoria, 76 (I): 67-83. https://doi.org/Io.3989/tp.20I9.I2226

Blasco, C., Liesau, C., Ríos, P., Gómez, J.L. y Flores, R. (20I4): "Un enterramiento múltiple del yacimiento calcolítico de Humanejos (Parla, Madrid) desde una perspectiva tafonómica: agrupando y reagrupando familia". Cuadernos de Prehistoria y Arqueología de la Universidad Autónoma de Madrid, 40: II-29.

Boessneck, J. (I969): "Osteological differences between sheep (Ovis aries Linné) and goats (Capra hircus Linné)". En D. Brothwell y E. Higgs (eds.): Science in Archaeology. London: 331-358.

Castro Curel, Z. (I988): "Peines prehistóricos peninsulares". Trabajos de Prehistoria, 45: 243-258.

Colmenarejo, R., Galán, C., Martínez, J. y Sánchez Meseguer,J. (1987): "La Motilla de Santa María del Retamar (Argamasilla de Alba, Ciudad Real)". Oretum, 3: 80-108.

Cucchi, T., Vigne, J. y Auffray, J.C. (2005): “First occurrence of the house mouse (Mus musculus domesticus Schwarz \& Schwarz, 1943) in the Western Mediterranean: a zooarchaeological revision of subfossil occurrences". Biological Journal of Linnean Society, 84 (3): 429-445. https://doi. org/Io.IIII/j.I095-8312.2005.00445.x

Choyke, A. M. y Bartosiewicz, L. (2009): "Telltale tools from a tell: Bone and antler manufacturing at Bronze Age Jászdózsa-Kápolnahalom”. Tiscium, XX: 357-376.

Daza Perea, A. (20II): "Los depósitos de perros en Camino de las Yeseras". En C. Blasco, C. Liesau y P. Ríos (eds.): Yacimientos calcolíticos con Campaniforme en la región de Madrid: nuevos estudios. Patrimonio Arqueológico de Madrid, 6: 2II-222. Universidad Autónoma de Madrid. Madrid.

Delibes de Castro, G., Fernández Manzano, J. y Herrán Martínez,J.L. (1999): "Submeseta Norte". En G. Delibes de Castro y I. Montero Ruiz (coords.): Las primeras etapas metalúrgicas en la Peninsula Ibérica II. Estudios regionales. Instituto Universitario Ortega y Gasset. Ministerio de Cultura. Madrid: 63-94.
Delibes de Castro, G., Esparza Arroyo, E., Velasco Vázquez, J., Zapatero Magdaleno, P., Fernández Rodríguez, C., Carbajo Arana, M., Palomo Díez, S. y Misiego Tejeda, J., (2019): "Dos tumbas individuales calcolíticas en las inmediaciones de los dólmenes de Osorno y Simancas: estudio bioantropológico, ofrenda de perros y 'postvida' megalítica en el valle medio del Duero". Trabajos de Prehistoria, 76 (2): 236-253. https://doi.org/Io.3989/ tp.2019.12235

Delvene, G., Baeza, E.y Benítez de Lugo Enrich, L. (2018): "Paleontología aplicada: origen de una estela funeraria de un lugar ceremonial prehistórico de Castillejo del Bonete (Terrinches, Ciudad Real, España)". En N. Vaz y A.A. Sá (eds.): Yacimientos paleontológicos excepcionales en la Peninsula Ibérica (XXXIV Jornadas de Paleontología y IV Congreso ibérico de Paleontología. Cuadernos del Museo Geominero, 27. Instituto Geológico y Minero de España. Madrid. 3I-38.

Dobson, M. (1998): "Mammal distributions in the western Mediterranean: the role of human intervention". Mammal Review, 28 (2): 77-88.

Domínguez García, A. C., Laplana, C., Sevilla, P., Blain, H.-A., Palomares Zumajo, N. y Benítez de Lugo Enrich, L., (2019a): "New data on the introduction and dispersal process of small mammals in southwestern Europe during the Holocene: Castillejo del Bonete site (southeastern Spain)". Quaternary Science Revierws, 225: 106008.

Domínguez García, A.C., Laplana, C., Sevilla, P., Guisado di Monti,J.C.y Bernárdez Gómez,M.J. (2019b): "Tafonomía y cronología de la asociación de micromamíferos de la Cueva del Estrecho (Villares del Saz, Cuenca)". Spanish Journal of Palaeontology, 34(2): 24I-256. https://doi 10.7203/ sjp.34.2.I6II4

Driesch, A.von den y Boessneck,J.(I980): "Die Motillas von Azuer und Los Palacios (Prov. Ciudad Real)“. Untersuchungen der Tierknochenfunde. Studien über frühe Tierknochenfunde von der Iberischen Halbinsel, 7: 84-I2I.

Esteban, C. y Benítez de Lugo Enrich, L. (2016): "Archaeoastronomy in Bronze Age sites of La Mancha (Spain)". Mediterranean Archaeology and Archaeometry, I6 (4): 283-289. doi: I0.528I/ zenodo.220948

Féderation Des Clubs CPN (ed.) (20Io): "Pelotes! Décortiquer et déterminer le contenu des pelotes de réjection". Les cabiers techniques de la Gazette des Terriers, I2I: I-98. 
Fernández Martín, S., Benítez de Lugo Enrich, L., y Palomares, N. (20I5): "La cerámica del yacimiento arqueológico Castillejo del Bonete (Terrinches, Ciudad Real). Estudio morfológico y tecnológico". Complutum, 26 (I): I33-152. http://dx.doi. org/Io.5209/rev_CMPL.2015.v26.nI.49344

Fonseca, R. (1984-1985): "Utillaje y objetos de adorno óseos en el Bronce de La Mancha”. Cuadernos de Prehistoria y Arqueología de la Universidad Autónoma de Madrid, II-I2: 47-56.

García Barbo A.B., Rodríguez Hidalgo, A.J., Morales, J.I., Martinell, J., Cebriá, A., Blasco, R. y Rosell, J. (20I4): "La malacofauna marina de las fases holocenas de la Cueva del Toll (Moià, Barcelona): nuevas aportaciones para el Neolítico nororiental". Archaeofauna, 23: I05-II5.

García Pérez, T. (1987): "La motilla de Los Romeros (Alcázar de San Juan, Ciudad Real)”. Oretum, 3: III-I65.

García Puchol, O. y Juan Cabanilles, J. (2010): "Las grandes láminas de sílex del ámbito valenciano. Estado de la cuestión”. Europa al final de la Prehistòria. Monografies, I3. Museu d'Arqueologia de Catalunya, Actes Museu d'Arqueologia de Catalunya. Barcelona: 99-106.

Garrido-Pena, R. (200o): El Campaniforme en La Meseta Central de la Península Ibérica (c. 25002000 a.C.). British Archaeological Reports International Series 892. Archaeopress. Oxford.

Harrison, R.J. y Gilman, A. (1977): "Trade in the second and third millennia B.C. between the Maghreband Iberia". Ancient Europe and the Mediterranean. Warminster: 90-IO4.

Klein, R.G. y Uribe, K. (1984): "The analysis of animal bones from archaeological sites". En K.W. Butzer y L.G. Freeman (eds.): Prehistoric archeology and ecology series. The University of Chicago press. Chicago.

Lalis, A., Mona, S., Stoetzel, E., Bonhomme, F., Souttou, K., Ouarour, A., Aulagnier, S., Denys, C. y Nicolas, V. (2019): "Out of Africa: demographic and colonization history of the Algerian mouse (Mus spretus Lataste)". Heredity, I22: I50-I7I. https://doi.org/Io.Io38/s4I437-oI8-oo89-7

Lenguazco González, R. (20I2): Estudio de materiales y análisis de su relación con los contextos excavados en la Motilla del Retamar (Argamasilla de Alba, Ciudad Real). Monografías Aqueoy+ 3. Madrid.
Liesau, C. (2012): "Depósitos con ofrendas de animales en yacimientos cogotas I: antecedentes y características". En J.A: Rodríguez Marcos y J. Fernández Manzano (eds.): Cogotas I, una cultura de la Edad del Bronce de la Peninsula Ibérica: 219-257.

Liesau, C. y Schubart. H. (2006): "Construcciones funerarias y materiales de origen orgánico en el ritual funerario de Fuente Álamo". Spal, I5: I3O-I43. Lillios, K.T., Blanco-González, A., Lee Drake, B. y López-Sáez, J.A. (2or6): "Mid-Late Holocene climate, demography, and cultural dynamics in Iberia: a multi-proxy approach". Quaternary Science Reviews, I35: I38-153.

López Padilla, J.A. (20II): Asta, hueso y marfil. Artefactos óseos de la Edad del Bronce en el Levante y Sureste de la Peninsula Ibérica (c. 2500-c.I300 cal BC). Museo Arqueológico de Alicante. Alicante. Maicas, R. (2007): Industria ósea y funcionalidad: Neolitico y Calcolítico en la cuenca de Vera. Bibliotheca Praehistorica Hispana, 24. CSIC. Madrid.

Molina González, F., Cámara Serrano, J. A., Afonso Marrero J.A. y Najera Colino, T. (20I4). Las sepulturas del Cerro de la Virgen (Orce, Granada). Diferencias cronológicas y sociales. Revista Atlántica-Mediterránea I6: I2I-I42

Montero, I., Benítez de Lugo Enrich, L., Álvarez García, H.J., Gutiérrez, P.C., Murillo, M., Palomares, N., Menchén, G., Moraleda, J. y Salazar-García, D.C. (20I4): "Cobre para los muertos. Estudio arqueométrico del material metálico procedente del monumento megalítico prehistórico Castillejo del Bonete (Terrinches, Ciudad Real-España)". Zephyrus, LXXIII: 109-I32. Salamanca. http://dx. doi.org/Io.I420I/zephyrus20I473109132

Morales Muñiz, A. (1986): "Análisis de la fauna de vertebrados recuperada en las sepulturas del poblado del Bronce del Cerro de la Encantada (Provincia de Ciudad Real)". Oretum, 2: 159-196. Morales Muñiz, A., Rubio, J. y Salcedo, B. (1987): "Informe faunístico sobre los restos óseos de la Motilla de Los Romeros". Oretum, 3: 152-I63.

Morales Muñiz, A., Cereijo Pecharroman, M.A., Hernández Carrasquilla, F.y Liesau Von LettowVorbeck, C. (1995): "Of mice and sparrows: commensal faunas from the Iberian Iron Age in the Duero Valley (Central Spain)". International Journal of Osteoarchaeology, 5(2): 127-I38. https:// doi.org/Io.1002/oa.I390050204 
Mujika Alustiza, J.A. (2007-2008): "La gestión de la materia prima ósea en la fabricación de objetos durante la Prehistoria". Veleia, 24-25: 531-568.

Nájera Colino, T (1982): La Edad del Bronce en La Mancha occidental. Tesis doctoral, Universidad de Granada, Granada.

Nocete, F. (200I): Tercer milenio a.n.e. Relaciones y contradicciones centro/periferia en el Valle del Guadalquivir. Bellaterra. Barcelona.

Odriozola, C., Benítez de Lugo Enrich, L., Villalobos, R., Martínez-Blanes, J.M., Avilés, Palomares, N., Benito,M.,Menchén, G., Barrio, C.y Salazar-García, D.C. (2016): "Personal body ornamentation on the Southern Iberian Meseta: An archaeomineralogical study". Journal of Archaeological Sciences: Reports, 5: I56-I67.

Olalde, I., Mallick, S., Patterson, N., Rohland, N., Villalba, V., Dulias, K., Edwards, C.J., Gandini, F., Pala, M., Silva, M., Soares, P., Ferrando, M., Adamski, Broomandkhoshbacht, N.N., Cheronet, O., Culleton, B.J., Fernandes, D., Lawson, A.M., Mah, M., Oppenheimer,J., Stewardson, K.,Zhang, Z.,Jiménez, J.M., Jorge, I., Moyano, Salazar García, D.C., Castanyer, P., Santos, M., Tremoleda, J., Lozano, M., Fernández, J., Mujika, J.A., Barroso, C., Bermúdez, F.J., Burch, J., Coromina, N., Viguera, E., Vivó, D., Cebrià, A., Fullola, J.M., García-Puchol, O., Morales, J.I., Oms, X., Vergès, J.M., Díaz-Carvajal, A., Ollich-Castanyer, I., Silva, A.M., García, P., Alonso, C., Jiménez Echevarría,J., Moreno, A., Ramos, P., Ramos, J., Vijande, E., Lillios, K., Mack,J., Waterman,J., Delibes, G., Agustí, B., Codina,F., Esparza, A., De Prado, G., Estalrrich, A., Finlayson, C., Finlayson, G., Finlayson, S., Giles, F., Majó,T., Rosas, A., Velasco,J.,Aguilella Arzo, G., Barciela González, V., Benítez de Lugo, L., Benito, M., García, G., Hernández, M., Llanos, A., Carrión, Y., Collado, I., Fernández, A., López, D., Sanz, M., Blasco, C., Daura, J., De Pedro Michó, M.J., Diez, A.A., Flores, R., Francès, J., Garrido, R., Guerra, E., Herrero, A.M., Juan, J., Liesau, C., López, D., Mcclure, S.B., Merino, M., Oliver, A., Pascual, G., Ríos, P., Sanz, M., Vidal, J.M., Kennett, D.J. Richards, M.B., Werner Alt, K., Haak, W., Pinhasi, R., Lalueza, C., Reich, D., (2019): “The genetic history of the Iberian Peninsula over the last 8000 years". Science, 363: 1230-I234.
Orri Terrado, E. (2004): Estudio de los restos faunisticos recuperados en el yacimiento de Castillejo de Bonete (Terrinches, Ciudad Real). Informe inédito.

Oviespaña (2019): "Aumentan las exportaciones de queso manchego en 2018 en medio millón de kilos". Consulta: 26/o9/2020. https://www. oviespana.com/Articulos/2783II-Aumentanlas-exportaciones-de-queso-manchego-en-2018en-medio-millon-de-kilos.html

Palazón, S. (20I2): “Comadreja - Mustela nivalis". En A. Salvador y J. Cassinello (eds.): Enciclopedia Virtual de los Vertebrados Españoles. Museo Nacional de Ciencias Naturales. http://www.vertebradosibericos.org/mamiferos/musniv.html. Consulta: 26/9/2020

Pales, L. y Lambert, C. (1971): Atlas ostéologique des mammifères. Vol. I. Centre National de la Recherche Scientifique, Paris.

Pales, L. y García, M.A. (198I): Atlas ostéologique pour server à l'identification des mammifères du Quaternaire. Vol. 2. Centre National de la Recherche Scientifique. Paris.

Pascual Benito, J.L. (1996): "Los adornos neolíticos en el País Valenciano". Recerques del Museu d'Alcoi, 5: 17-52.

Pellicer Catalán, M. (1964): El Neolítico y el Bronce de la Cueva de la Carigüela de Piñar (Granada), Trabajos de Prehistoria del Seminario de Historia primitiva del hombre de la Universidad de Madrid y del instituto español de Prehistoria del C.S.I.C., XV Madrid.

Pérez-Romero, A., Carretero, J.M., Alday, A., Galindo-Pellicena, M.A., Adán, G., Juez, L.y Arsuaga, J.L. (2015): "La gestión del utillaje óseo de la Edad del Bronce en el yacimiento de El Portalón de Cueva Mayor, sierra de Atapuerca, Burgos". Complutum, 26 (I): II3-г3r.

Polo, E., Bueno, P., De Balbín, R., Benítez de Lugo Enrich, L., Palomares, N. (20I5): "Manifestaciones gráficas en la Cueva-Sima del Castillejo del Bonete (Terrinches, Ciudad Real)". Arpi, 2: 90-Iо7.

Rodanés, J.M. (1987): La industria ósea prehistórica en el Valle del Ebro. Cometa. Zaragoza.

Román, J. (2019): "Manual para la identificación de los cráneos de los roedores de la península ibérica, islas baleares y canarias". Manuales de Mastozoologia: I-I2I, SECEM. Madrid. 
Salazar-García, D.C., Benítez de Lugo Enrich, L., Álvarez, H.J. y Benito, M. (2013): "Estudio diacrónico de la dieta de los pobladores antiguos de Terrinches (Ciudad Real) a partir del análisis de isótopos estables sobre restos óseos humanos". Revista Española de Antropología Fisica, 34: 6-I4. Salazar-García D.C., Aura E., Olària C., Talamo S., Morales J.V., y Richards M.P. (20I4). “Isotope evidence for the use of marine resources in the Eastern Iberian Mesolithic". Journal of Archaeological Science, 42: 23I-240.

Schuhmacher, T.X., Banerjee, A., Dindorf, W. Sastri, Ch.y Sauvage, T. (2013): "The use of sperm whale ivory in Chalcolithic Portugal”. Trabajos de Prehistoria, 70-I: 185-203.

Schmid,E. (1972): Atlas of animal Bones-Tierknocheatlas. Elsevier Publishing Company. London.

Serrano, M., Esteban, C., Gómez, F., Zafra, N. y Arias, F. (2017): "Los signos del tiempo: documentación e interpretación de los petroglifos calcolíticos de la Cueva del Toril (Ontiñar, Jaén)”. Menga, 8: II7-I4I.

Silver, I.A. (I980): "La determinación de la edad de los animales domésticos". Ciencia en Arqueología: 289-309.
Soler Díaz,J.A. (2002): Cuevas de inhumación múltiple en la Comunidad Valenciana. vol.r. Real Academia de la Historia. Madrid.

Stoetzel, E. (20I3): "Late Cenozoic micromammal biochronology of northwestern Africa". Palaeogeography, Palaeoclimatology, Palaeoecology, 392: 359-38r. https://doi.org/ro.Ior6/j.palaeo.2013.09.026 Uscatescu, A. (1992): Los botones de perforación en ' $V$ ' en la Península Ibérica y las Baleares durante la Edad de los metales. Temas de Arqueología 2. Foro Arqueología, Proyectos y Publicaciones, S.L. Madrid.

Virgós, E., Revilla, E., Mangas, J.G., Barea-Azcón, J.M.,Rosalino, L.M. y de De Marinis, A.M. (2005): "Revisión de la dieta del tejón (Meles meles) en la Península Ibérica: comparación con otras localidades de su área de distribución natural". En E. Virgos, E. Revilla,J.G. Mangas y X. Domingo-Roura (eds.): Ecología y Conservación del Tejón en Ecosistemas Mediterráneos. Sociedad Española para la Conservación y Estudio de los Mamíferos (SECEM). Málaga: 67-80. 